\title{
Functional Dissection of a Neuronal Network Required for Cuticle Tanning and Wing Expansion in Drosophila
}

\author{
Haojiang Luan, ${ }^{1 \star}$ William C. Lemon, ${ }^{1 \star}$ Nathan C. Peabody, ${ }^{1}$ Jascha B. Pohl, ${ }^{1}$ Paul K. Zelensky, ${ }^{1}$ Ding Wang, ${ }^{1}$ \\ Michael N. Nitabach, ${ }^{2}$ Todd C. Holmes, ${ }^{3}$ and Benjamin H. White ${ }^{1}$ \\ ${ }^{1}$ Laboratory of Molecular Biology, National Institute of Mental Health, National Institutes of Health, Bethesda, Maryland 20892, ${ }^{2}$ Department of Cellular \\ and Molecular Physiology, Yale University School of Medicine, New Haven, Connecticut 06520, and ${ }^{3}$ Department of Biology, New York University, New \\ York, New York 10003
}

\begin{abstract}
A subset of Drosophila neurons that expresses crustacean cardioactive peptide (CCAP) has been shown previously to make the hormone bursicon, which is required for cuticle tanning and wing expansion after eclosion. Here we present evidence that CCAP-expressing neurons $\left(\mathrm{N}_{\mathrm{CCAP}}\right)$ consist of two functionally distinct groups, one of which releases bursicon into the hemolymph and the other of which regulates its release. The first group, which we call $\mathrm{N}_{\mathrm{CCAP}^{-}}-\mathrm{C} 929$, includes 14 bursicon-expressing neurons of the abdominal ganglion that lie within the expression pattern of the enhancer-trap line c929-Gal4. We show that suppression of activity within this group blocks bursicon release into the hemolymph together with tanning and wing expansion. The second group, which we call $\mathrm{N}_{\mathrm{CCAP}}-\mathrm{R}$, consists of $\mathrm{N}_{\mathrm{CCAP}}$ neurons outside the $\mathrm{c} 929-\mathrm{Gal} 4$ pattern. Because suppression of synaptic transmission and protein kinase A (PKA) activity throughout $\mathrm{N}_{\mathrm{CCAP}}$, but not in $\mathrm{N}_{\mathrm{CCAP}^{-}}-\mathrm{C} 929$, also blocks tanning and wing expansion, we conclude that neurotransmission and PKA are required in $\mathrm{N}_{\mathrm{CCAP}}-\mathrm{R}$ to regulate bursicon secretion from $\mathrm{N}_{\mathrm{CCAP}^{-}} \mathrm{C} 929$. Enhancement of electrical activity in $\mathrm{N}_{\mathrm{CCAP}}-\mathrm{R}$ by expression of the bacterial sodium channel $\mathrm{NaChBac}$ also blocks tanning and wing expansion and leads to depletion of bursicon from central processes. $\mathrm{NaChBac}$ expression in $\mathrm{N}_{\mathrm{CCAP}^{-}} \mathrm{C} 929$ is without effect, suggesting that the abdominal bursicon-secreting neurons are likely to be silent until stimulated to release the hormone. Our results suggest that $\mathrm{N}_{\mathrm{CCAP}}$ form an interacting neuronal network responsible for the regulation and release of bursicon and suggest a model in which PKA-mediated stimulation of inputs to normally quiescent bursicon-expressing neurons activates release of the hormone.
\end{abstract}

Key words: excitability; network; circuit; hormone; neuropeptide; Drosophila

\section{Introduction}

Crustacean cardioactive peptide (CCAP)-expressing neurons $\left(\mathrm{N}_{\mathrm{CCAP}}\right)$ in Drosophila play a critical role in both pupal development and early adult maturation (Park et al., 2003). Animals in which $\mathrm{N}_{\mathrm{CCAP}}$ have been ablated typically die as pupae with head eversion defects, but those that survive to adulthood retain the "juvenile" features of newly eclosed adults, including unexpanded wings and soft, poorly pigmented bodies. This persistent juvenile phenotype is likely to result from loss of the hormone

Received Sept. 15, 2005; revised Nov. 18, 2005; accepted Nov. 22, 2005.

This research was supported by the Intramural Research Program of the National Institutes of Health, National Institute of Mental Health (B.H.W), National Science Foundation Grants IBN-0323466 and IBN-0092753, National Institutes of Health Grant R01-NSO46750 (T.C.H.), and an Individual Postdoctoral National Institutes of Health National Research Service Award (M.N.N.). We thank Jae Park, David Clapham, Mark Halfon, and Tzumin Lee for plasmids, the Bloomington Stock Center and the National Institute of Neurological Disorders and Stroke sequencing facility for stocks and services, and Chi-hon Lee, Harold Gainer, and Paul Taghert for valuable comments on this manuscript. Special thanks to John Ewer and James Hopper for generously supplying anti-CCAP and anti-Gal80 antibodies, respectively. We also thank Howard Nash for advice and encouragement throughout the course of the work described here.

*H.L. and W.C.L. contributed equally to this work

Correspondence should be addressed to Benjamin White, National Institute of Mental Health, National Institutes of Health, 9000 Rockville Pike, Bethesda, MD 20892. E-mail: benjaminwhite@mail.nih.gov.

W. C. Lemon's present address: Department of Biological Sciences, P.0. Box 43131, Texas Tech University, Lubbock, TX 79409.

D01:10.1523/JNEUROSCI.3916-05.2006

Copyright $\odot 2006$ Society for Neuroscience $\quad$ 0270-6474/06/260573-12\$15.00/0 bursicon (for review, see Reynolds, 1983; Ewer and Reynolds, 2002), which is normally released into the hemolymph shortly after eclosion and is known from genetic studies to be required for both wing expansion and tanning. Bursicon has been shown to be expressed exclusively in $\mathrm{N}_{\mathrm{CCAP}}$ during larval development (Park et al., 2003; Luo et al., 2005), but its distribution in adults has not been investigated.

In other insects, bursicon bioactivity in emerging adults is most abundant in the ventral nervous system (Fraenkel and Hsiao, 1965; Truman, 1973; Taghert and Truman, 1982b), and evidence indicates that the hormone is released into the hemolymph from neurons in the abdominal ganglia. Bursicon also appears to be made in the brain and subesophageal ganglion (SEG) (Taghert and Truman, 1982a; Honegger et al., 2002), in which it may play a role in regulating posteclosion behavior (Baker and Truman, 2002). The cellular and molecular pathways underlying regulation of bursicon secretion at any of these sites is unknown.

Manipulations of neuronal function in Drosophila that produce animals with tanning and wing expansion deficits have suggested possible physiological determinants of bursicon secretion. Within $\mathrm{N}_{\mathrm{CCAP}}$, disruption of membrane excitability and synaptic transmission, by constitutive suppression of either Shaw $\mathrm{K}^{+}$ channel expression (Hodge et al., 2005) or dynamin function 
(Park et al., 2003), yields animals with the juvenile phenotype. Similarly, manipulations of the protein kinase A (PKA) pathway also produce juvenile phenotypes, but the cellular locus of action of these manipulations has not been determined (Bantignies et al., 2000; Rodan et al., 2002).

To define the role(s) of $\mathrm{N}_{\mathrm{CCAP}}$ in bursicon release and to better understand the molecular and cellular determinants of tanning and wing expansion in Drosophila, we have characterized the adult distribution of bursicon and shown that the hormone localizes to a subset of $\mathrm{N}_{\mathrm{CCAP}}$ primarily included in the expression pattern of the enhancer-trap line c929-Gal4 (Hewes et al., 2003). We have compared the physiological effects of targeted manipulations of $\mathrm{N}_{\mathrm{CCAP}}$, and of the subset of $\mathrm{N}_{\mathrm{CCAP}}$ within the $\mathrm{c} 929-\mathrm{Gal} 4$ pattern $\left(\mathrm{N}_{\mathrm{CCAP}}-\mathrm{c} 929\right)$, to show that $\mathrm{N}_{\mathrm{CCAP}}$ consists of two functionally distinct groups of neurons that interact to regulate release of bursicon into the hemolymph from the abdominal ganglion in a PKA-dependent manner. By exploiting tools for the incremental suppression of excitability, which permit investigation of adult physiological phenotypes but avoids developmental lethality, and a novel tool for selectively enhancing neuronal excitability, the bacterial sodium channel $\mathrm{NaChBac}$ (Ren et al., 2001), we also infer differential roles of neuronal activity in the two $\mathrm{N}_{\text {CCAP }}$ groups.

\section{Materials and Methods}

Fly stocks. Flies were raised on standard corn meal-molasses medium and maintained at $25^{\circ} \mathrm{C} / 65 \%$ relative humidity on a constant $12 \mathrm{~h}$ light/dark cycle. Transgenic lines used in this study were generous gifts from the following: $y w$; CCAP-Gal4; + and $y w$; +; CCAP-Gal4 (Park et al., 2003) (John Ewer, Cornell University, Ithaca, NY); w; c929-Gal4; + (O'Brien and Taghert, 1998) (Paul Taghert, Washington University, St. Louis, MO); w; +;UAS-Kir2.1-EGFP7 (Paradis et al., 2001) (Graeme Davis, University of California, San Francisco, San Francisco, CA); w; UASTNT-E;+; $w ;+; U A S-T N T-K / T M 3$ and the inactive tetanus toxin lines UAS-TNT-V1-A and UAS-TNT-Q4-A1 (Sweeney et al., 1995) (Cahir O'Kane, University of Cambridge, Cambridge, UK); $w$; +; UAS-PKA ${ }^{\text {inh }}$ (Li et al., 1995) and the inactive control $w ; P K A^{m-i n h} ;+$ (Kiger and O'Shea, 2001) (both from Ulrike Heberlein, University of California, San Francisco, San Francisco, CA); w; +;UAS-Shits (Kitamoto, 2001) (Toshi Kitamoto, University of Iowa, Iowa City, IA); and $y w$;UAS-2XEGFP; UAS-2XEGFP (Halfon et al., 2002) (Haig Keshishian, Yale University, New Haven, CT). The $w, r p r ;+;+, w$ and Canton-S lines were from the Bloomington Stock Center (Indiana University, Bloomington, IN). The $1 \times, 2 \times$, and $3 \times$ electrical knock-out $(\mathrm{EKO})$ lines have been described previously (White et al., 2001).

Construction of UAS-NaChBac-EGFP and CCAP-Gal80 constructs and fly lines. The NaChBac cDNA (Ren et al., 2001) was truncated 16 nucleotides $5^{\prime}$ of the stop codon by cleavage with HindIII and fused in frame to enhanced green fluorescent protein (EGFP) (Clontech, Mountain View, $\mathrm{CA})$ to generate $\mathrm{NaChBac-GFP}$ before subcloning into the pUAST plasmid for P-element transformation. To construct CCAP-Gal80, two copies of the Gal80 cDNA (gift from Tzumin Lee, University of Massachusettes, Worcester, MA) were cloned into the pBS II KS+-internal ribosomal entry site (IRES) vector (gift from Marc Halfon, State University of New York, Buffalo, Buffalo, NY) to generate a Gal80-IRES-Gal80 construct flanked by NotI and XhoI. A DNA fragment extending from -516 to +39 bp of the DmCCAP transcription start site (kind gift from Jae Park, University of Tennessee, Knoxville, TN) was subcloned into the pPUAST plasmid after excision of the 5XUAS and heat shock protein 70 TATA box sequences with PstI and BglII, and the tandem Gal80 fragment was ligated into unique NotI and XhoI sites to generate pCCAP-Gal80IRES-Gal80. P-element injections and isolation of transformants was performed for both plasmids by Genetic Services (Cambridge, MA). A second chromosome insert of UAS-NaChBac-EGFP (B16-B, also called $\mathrm{NaChBac4}$ ) and third chromosome insert of CCAP-Gal80 (ET3-C3B) were used in this paper.
Manipulation of neuronal function and scoring of phenotypes. Experimental crosses between Gal4 driver and UAS-effector lines were typically set up with parallel control crosses of the driver to Canton-S. Unless otherwise noted, the CCAP-Gal4 crosses reported here used the line with the third chromosome insert, although both lines gave similar results. Wing phenotypes were scored at least $24 \mathrm{~h}$ after eclosion to ensure that the final phenotype had been attained. As the wing expands, the acutely bent distal tip opens to $180^{\circ}$ to become even with the proximal portion of the wing. The remaining folds then open with the notch at the costal elbow unfolding last to give the wings a cupped appearance, followed by a final flattening. Flies were scored as "unexpanded" (UEW) if the distal tip of the folded wing had assumed an angle of $\leq 90^{\circ}$ relative to the proximal portion of the wing and as "expanded" (EW) if they had attained at least the cupped state. Partially expanded wing flies (PEW) had intermediate wing morphologies. Cuticle tanning was scored in experimental flies and controls (matched for age and sex) that were isolated after eclosion within $15 \mathrm{~min}$ of each other and aged for $3 \mathrm{~h}$. Photographs taken of experimental and control flies side-by-side under equivalent illumination were converted to grayscale using Adobe Photoshop (Adobe Systems, San Jose, CA), and average grayscale pixel intensities of the thoracic cuticles were subtracted to obtain a "tanning difference score." Average pixel intensities were determined as follows: a circular region of interest (ROI), the diameter of which (in pixels) was one-fourth of the distance between the cervix and the scutellum, was placed over two representative regions of thorax (free of reflections or other atypical features) on both the experimental and control flies. The mean pixel intensity (on a scale of $0-255$, with $0 \equiv$ black and $255 \equiv$ white) for each ROI was determined using the Photoshop Histogram tool, and the two mean values were averaged for each fly. If multiple control flies were present in the photographed group, an average value for all controls was calculated from the values of the individual control flies. The average pixel intensity of the experimental fly was then subtracted from the control value. The tanning difference scores from all experimental flies from a cross were then averaged to obtain the final score. Paired Canton-S flies $0 \mathrm{~h}$ (i.e., untanned) and $3 \mathrm{~h}$ (tanned) after eclosion were used to validate this assay. The tanning difference score between 3 and $0 \mathrm{~h}$ (newly eclosed) flies was $23.5 \pm 12.3$ (SD) $(n=36)$. In crosses in which parental genotypes included the yellow gene (y), only males lacking y or females heterozygous at this locus were scored for tanning.

Electroretinograms. Adult flies ( $\leq 24 \mathrm{~h}$ old) were anesthetized and secured (including all appendages) to a microscope slide with double-sided tape and cyanoacrylate glue so that one eye faced upward. The retina was impaled with a glass microelectrode filled with $3 \mathrm{~m} \mathrm{~K}$-acetate $(8-10 \mathrm{M} \Omega)$, and a similar reference electrode was placed in the thorax. After dark adaptation for $20 \mathrm{~min}$, a series of $4 \mathrm{~s}$ white light stimuli [intensity value $\left.(I), \sim 40 \mathrm{~mW} / \mathrm{cm}^{2}\right)$ ] were delivered to the retina through a fiber optic illuminator and computer-controlled shutter at $1 \mathrm{~min}$ intervals. Photoresponses were amplified with a Dagan (Minneapolis, MN) IX2-700 amplifier, digitized at $20 \mathrm{kHz}$, and recorded on a computer using PowerLab hardware and software (ADInstruments, Grand Junction, CO). The first five stimuli were averaged to produce representative electroretinograms (ERG).

Antibodies. Rabbit antisera to CCAP (Ewer and Truman, 1996) were the generous gift of John Ewer. Mouse antibodies to the bursicon $\beta$-subunit (Luo et al., 2005) were provided by Aaron Hsueh (Stanford University, Stanford, CA). Rabbit polyclonal antisera against Gal80, kindly provided by James Hopper (Penn State College of Medicine, Hershey, PA), were raised against a trpE-Gal80 fusion protein expressed in E. coli from a pATH1 vector by T. Torchia (Penn State College of Medicine, Hershey, PA) and J. E. Hopper following the general methods described by Spindler et al. (1984). (Work by T. Torchia and J. E. Hopper was supported by National Institutes of Health Grant RO1 GM27925, awarded to J.E.H.) The affinity-purified rabbit antibody to the bursicon $\alpha$-subunit was prepared commercially using the peptide CEGPLNNHFRRIALQ, which contains the $\mathrm{C}$ terminus of the bursicon $\alpha$-subunit. This peptide was maleimide coupled to keyhole limpet hemocyanin for use as an immunogen. The $\alpha$ - and $\beta$-subunits of bursicon have also been called bursicon and partner-of-bursicon (pburs) (Luo et al., 2005). To avoid ambiguity between the subunit names and the name of 
the active hormone, which is a dimer of both subunits, we follow the nomenclature of Mendive et al. (2005) in calling the subunit encoded by CG13419 the $\alpha$-subunit and the subunit encoded by CG15284 the $\beta$-subunit. We refer to the antibodies specific for the two subunits antiburs $\alpha$ and anti-burs $\beta$, respectively.

Immunohistochemistry and microscopy. Pharate adults [pupal stage P15i (Bainbridge and Bownes, 1981)] were dissected in PBS, and the excised nervous systems were fixed in $4 \%$ paraformaldehyde in PBS for $20-30 \mathrm{~min}$, followed by postfixation in $4 \%$ paraformaldehyde plus $0.5 \%$ Triton X-100 for $15 \mathrm{~min}$. Samples were then washed in PBT (PBS plus $0.1 \%$ Triton X-100) for 15 min, placed in blocking solution (PBT plus $5 \%$ normal goat serum plus $0.5 \%$ bovine serum albumin) for $2 \mathrm{~h}$ at room temperature, followed by overnight incubation at room temperature in primary antibodies diluted in blocking solution (rabbit anti-CCAP, 1:5000; rabbit anti-burs $\alpha, 1: 5000$; mouse anti-burs $\beta, 1: 1000)$. The tissue was washed for $30 \mathrm{~min}$ in PBT and five times for $30 \mathrm{~min}$ in blocking solution before incubating for $2 \mathrm{~h}$ at room temperature in secondary antibodies diluted in blocking solution (AlexaFluor 568 goat anti-rabbit, 1:500; AlexaFluor 680 goat anti-mouse, 1:500; Invitrogen, Carlsbad, CA). The excised nervous systems were then washed four times for $20 \mathrm{~min}$ in PBT and mounted in VectaShield (Vector Laboratories, Burlingame, CA) on glass cover slides for fluorescence imaging with a Nikon (Tokyo, Japan) C-1 confocal microscope. $Z$-series through either the brain or ventral nerve cord of each sample were acquired in $1 \mu \mathrm{m}$ increments using a $20 \times$ objective. The argon (488 nm), helium-neon $(543 \mathrm{~nm})$, and helium-neon $(633 \mathrm{~nm})$ laser emission lines were used for fluorophore excitation. The presented images are composites of separately acquired volume-rendered images of the brain and ventral nerve cord.

Analysis of expression patterns and immunoreactivity. The patterns of CCAP and bursicon immunoreactivity varied somewhat between individuals, as did the expression pattern of EGFP driven by CCAP-Gal4 and c929-Gal4. To represent the frequency and intensity of labeling of individual identified $\mathrm{N}_{\mathrm{CCAP}}$ neurons with each antibody and driver, we created consensus expression patterns derived from multiple CNS preparations of each genotype. To determine the patterns of bursicon $\alpha$ - and $\beta$-subunit expression within $\mathrm{N}_{\mathrm{CCAP}}$, we scored CNS preparations from CCAP-Gal4>UAS-EGFP animals labeled with rabbit anti-burs $\alpha$ and mouse anti-burs $\beta$ antibodies. Each focal plane of the confocal $z$-stack was evaluated for overlapping bursicon immunolabeling in the CCAP neuron (i.e., EGFP-positive) somata. The intensity of immunolabeling of each soma in each preparation was scored on a scale of $0-3$. The frequency $(\nu)$ with which a given neuron was labeled was calculated by dividing the number of preps in which that neuron had a non-zero intensity by the total number of preparations. The consensus intensity value $(I)$ for a given neuron was calculated by averaging all non-zero values for this neuron across preparations. To determine the overlap of the c929-Gal4 expression pattern with that of CCAP and bursicon, the same procedure was performed on c929-Gal4>UAS-EGFP CNS preparations triple-labeled for $\mathrm{c} 929$ (EGFP), CCAP (using rabbit anti-CCAP antibodies), and bursicon $\beta$-subunit (using mouse anti-burs $\beta$ antibodies). In these cases, the consensus expression patterns show only the intensity and frequency of labeling (c929-Gal4>UAS-EGFP or bursicon) within the CCAP expression pattern.

To quantify bursicon levels in animals expressing UAS-effectors under the control of either CCAP- or c929-Gal4, CNS preparations were stained with the anti-burs $\alpha$ antibody and imaged by confocal microscopy. Volume-rendered images of this staining were converted to grayscale, and the intensity of neurite staining in defined anatomical regions (brain, subesophageal ganglion, the three thoracic ganglia, and the abdominal ganglion) was scored blind on a scale of $0-3$ without knowledge of preparation genotype. A total score was determined for each animal by adding the individual scores for each anatomical region, and these scores were evaluated for statistically significant differences between genotypes using a nonparametric alternative to ANOVA [Kruskal-Wallis test (Sokal and Rohlf, 1995) with post hoc comparisons (Conover, 1999)]. Two groups of compiled scores were independently evaluated: one from animals in which CCAP-Gal4 was driving expression of $3 \times \mathrm{EKO}$, $\mathrm{PKA}^{\text {inh }}$, NaChBac-EGFP, or EGFP, and a second from animals in which
c929-Gal4 was driving $3 \times$ EKO, PKA ${ }^{\text {inh }}$, NaChBac-EGFP, or nothing (i.e., crossed to Canton-S).

Hemolymph collection and immunoblotting. Recently eclosed flies, all collected within $60 \mathrm{~min}$ of eclosion, were anesthetized with $\mathrm{CO}_{2}$ and impaled between the base of the wing and the mesothoracic limb with a blunted glass micropipette. Impaled flies were then centrifuged together in a multiply perforated (with a 25 gauge needle) $0.5 \mathrm{ml}$ microcentrifuge tube placed inside a second $1.5 \mathrm{ml}$ microcentrifuge tube at $2000 \times g$ for 1 min. The hemolymph (in the $1.5 \mathrm{ml}$ tube) was collected in 0.5 or $1.0 \mu \mathrm{l}$ aliquots in microcapillary pipettes (Drummond Scientific, Broomall, $\mathrm{PA})$ and then placed into a solution of HE buffer (100 mM KCl, $20 \mathrm{~mm}$ HEPES, pH 7.5, 5\% glycerol, 10 mm EDTA, and 0.1\% Triton X-100) with $3 \times$ HALT protease inhibitor cocktail (Pierce, Rockford, IL) and $0.5 \mathrm{M}$ EDTA. Samples were immediately frozen on dry ice and then supplemented with an equal volume of Laemmli's sample loading buffer (Laemmli, 1970) containing 5\% $\beta$-mercaptoethanol (Sigma, St. Louis, MO) before storage at $-20^{\circ} \mathrm{C}$. Approximately $6-10$ flies were required to collect $500 \mathrm{nl}$ of hemolymph, and up to 20 could be centrifuged at one time. Samples ( $500 \mathrm{nl}$ hemolymph per lane) were prepared for electrophoresis by denaturation at $100^{\circ} \mathrm{C}$ for $5 \mathrm{~min}$ and then resolved on $12-4 \%$ (resolving-stacking) Tris- $\mathrm{HCl}$ minigels (Bio-Rad, Hercules, CA) before transfer to $0.2 \mu \mathrm{m}$ nitrocellulose membranes (Invitrogen). Membranes were blocked overnight at $4{ }^{\circ} \mathrm{C}$ in blocking solution (3\% instant milk, PBS, and $0.05 \%$ Tween 20 ) and then incubated with rabbit anti-burs $\alpha$ antibody (diluted 1:5000 in blocking solution) for $1 \mathrm{~h}$ at room temperature. After five 15 min washes, membranes were incubated in peroxidaseconjugated anti-rabbit secondary antibody (Jackson ImmunoResearch, West Grove, PA) diluted 1:100,000 in blocking solution) for $1 \mathrm{~h}$, washed again, and then incubated in West Femto chemiluminescent substrate (Pierce) for $5 \mathrm{~min}$, before development on BioMax film (Eastman Kodak, Rochester, NY) for 1-5 min.

\section{Results}

\section{Bursicon is strongly expressed in $\mathrm{N}_{\mathrm{CCAP}}$ of the abdominal ganglion in pharate adults}

Adult Drosophila emerge from the pupal case with soft, unpigmented cuticle and compactly folded wings. Within the first hour, the wings are expanded by infusion of hemolymph, and, by $3 \mathrm{~h}$, the cuticle of the wings and body has been sclerotized and melanized in a process called tanning. Both wing expansion and cuticle tanning require the heterodimeric hormone bursicon, which is known from bioassays to be released into the hemolymph shortly after eclosion. Drosophila with mutations in genes encoding either the bursicon $\alpha$-subunit or the bursicon receptor rickets fail to both tan and expand their wings (Baker and Truman, 2002; Dewey et al., 2004). This phenotype is shared by adults in which $\mathrm{N}_{\text {CCAP }}$ have been selectively ablated by expression of the proapoptotic gene reaper (Park et al., 2003), and immunohistochemical analysis has shown that coexpression of bursicon subunits is restricted to four CCAP-immunopositive pairs of neurons in the ventral nerve cord in third-instar larvae. Together, these observations strongly implicate $\mathrm{N}_{\mathrm{CCAP}}$ as the source of bursicon required for wing expansion and tanning at the later adult stage.

To determine the identity of $\mathrm{N}_{\mathrm{CCAP}}$ neurons that express bursicon in the adult, we examined the distribution of bursicon immunoreactivity in the nervous systems of late-stage pharate adults (Fig. $1 A-D$ ). Each of 11 preparations expressing EGFP in $\mathrm{N}_{\mathrm{CCAP}}$ was probed with antibodies to the $\alpha$ - and $\beta$-subunits of bursicon and analyzed by confocal microscopy for colocalization of labeling. Figure $1 E$ shows the consensus distributions of the bursicon subunits with respect to the CCAP-Gal4>UAS-EGFP pattern, with the frequency $(\nu)$ and average intensity of labeling ( $I$ ) indicated. Robust bursicon subunit expression was restricted to neurons within $\mathrm{N}_{\mathrm{CCAP}}$, with consistent, high-level expression in the cell bodies of 14 dorsal neurons of the abdominal ganglion 
and in two ventrally disposed neurons of the subesophageal ganglion. We designate these neurons $\mathrm{B}_{\mathrm{AG}}$ and $\mathrm{B}_{\mathrm{SEG}}$, respectively. Strong expression was seen less frequently in the posterior pair of CCAP-expressing neurons in the third thoracic ganglion and in bilaterally symmetric $\mathrm{N}_{\mathrm{CCAP}}$ pairs in the mid-subesophageal ganglion and brain. Occasionally, weak bursicon immunoreactivity was seen outside of $\mathrm{N}_{\mathrm{CCAP}}$ in the thoracic ganglia, typically in single neurons or bilateral pairs (data not shown). Unlike what has been reported for the larval nervous system (Luo et al., 2005), no neurons in the adult exclusively expressed the $\alpha$-subunit, suggesting that bursicon heterodimers are typically formed in adult cells expressing bursicon subunits.

Bursicon-immunoreactive processes were also evident, most obviously in the nerves exiting the abdominal ganglion (Fig. 1D, arrowhead). The abundance of immunoreactivity in these nerves suggests that this bursicon may be destined for release into the hemolymph. However, immunolabeling of CNS preparations excised immediately after wing expansion did not show diminished labeling of these nerves or of the somata of the abdominal neurons (data not shown). Additional anatomical characterization will be required to determine the origin of the bursicon in the abdominal nerves and the timing and site(s) of its release. The more sensitive anti- $\alpha$-subunit antibody also labeled processes within the CNS in both the ventral nerve cord and the brain (Fig. $1 B$, arrows). This labeling was punctate and may represent sites of release of the hormone into the CNS.

Suppression of excitability in $\mathrm{N}_{\text {CCAP }}$ inhibits wing expansion and tanning The restriction of bursicon expression to $\mathrm{N}_{\mathrm{CCAP}}$ in late-stage pharate adults implies that the mechanisms of bursicon release can be studied by targeted manipulation of $\mathrm{N}_{\mathrm{CCAP}}$ physiology using the CCAP-Gal4 driver introduced by Park et al. (2003) in conjunction with appropriate UASeffector constructs. Previously, we have demonstrated the efficacy of targeted suppression of neuronal excitability in analyzing neuronal function (White et al., 2001; Nitabach et al., 2002). Applying this approach, we suppressed membrane excitability in $\mathrm{N}_{\mathrm{CCAP}}$ to ask whether hormone secretion requires electrical activity in these neurons. To suppress membrane excitability, we used CCAP-Gal4 to express two previously described $\mathrm{K}^{+}$channel constructs: UAS-EKO, a modified Shaker channel (White et al., 2001), and UAS-Kir2.1, a human inward rectifier (Johns et al., 1999; Baines et al., 2001). The EKO channel, which can be used to
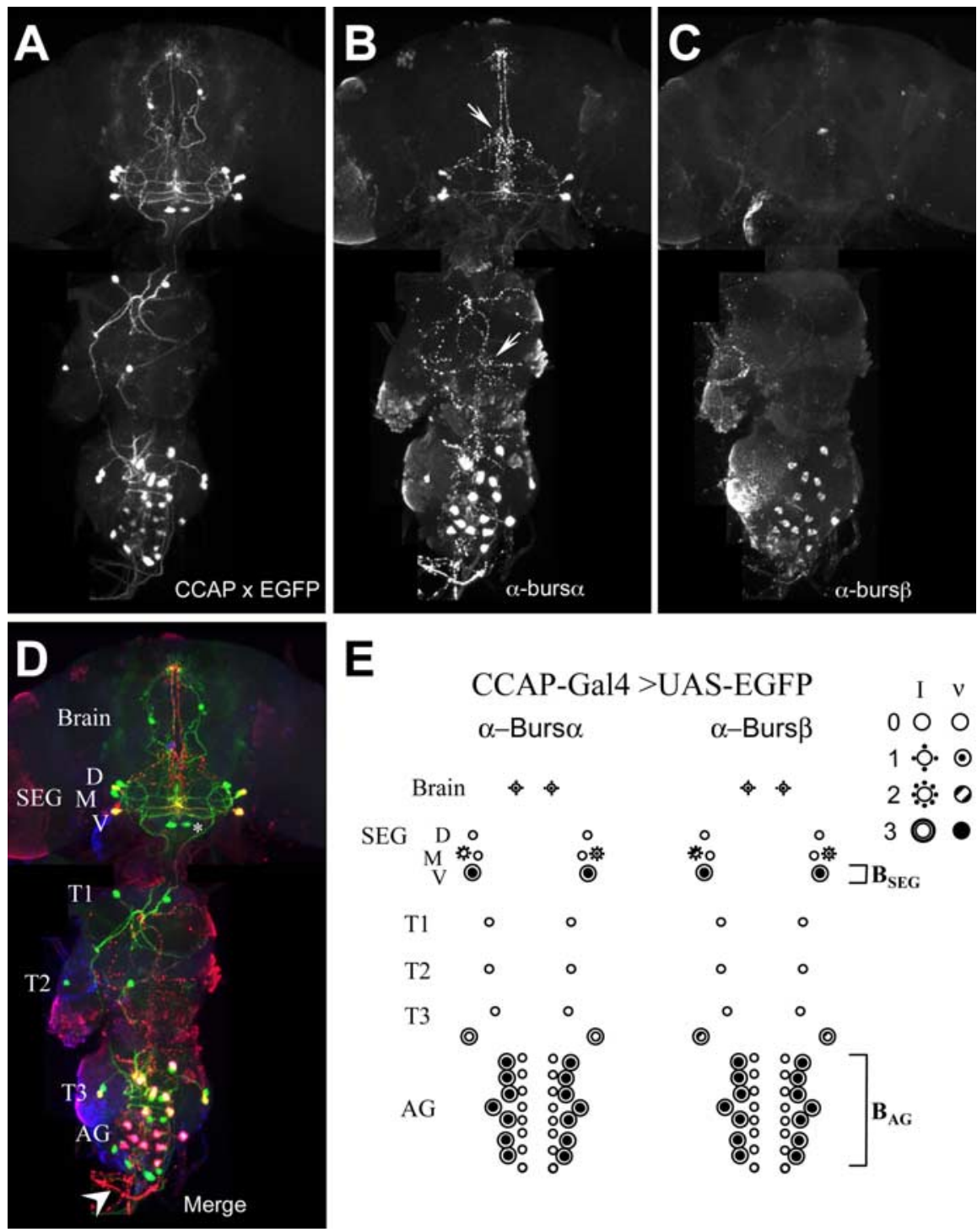

E

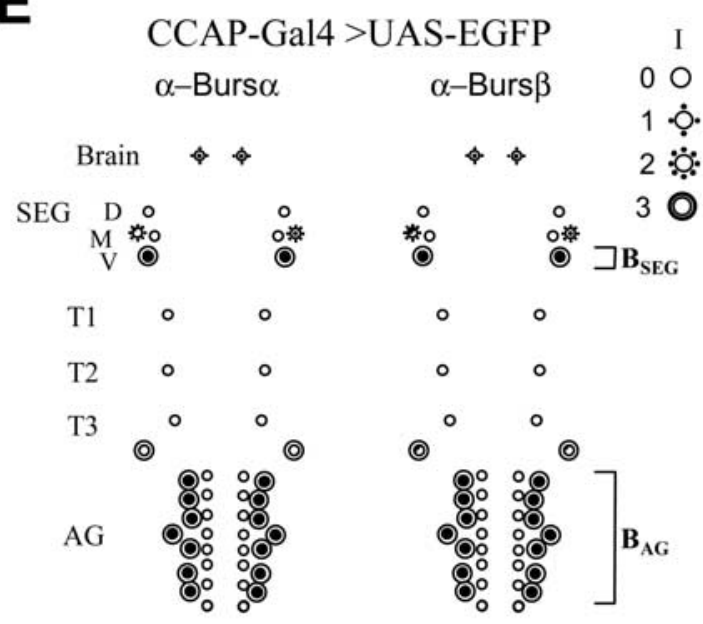

Figure 1. Expression of bursicon $\alpha$-and $\beta$-subunits is restricted to specific $\mathrm{N}_{\text {CCAP }}$ neurons in the pharate adult nervous system. $\boldsymbol{A}-\boldsymbol{D}$, Nervous systems excised from pharate adults expressing EGFP in $\mathrm{N}_{\text {CCAP }}(\boldsymbol{A})$ were double labeled with antibodies to both the bursicon $\alpha$-subunit $(\boldsymbol{B})$ and $\beta$-subunit $(\boldsymbol{C})$. In the merged image $(\boldsymbol{D})$, the green, red, and blue channels representEGFP, $\alpha$-subunit, and $\beta$-subunit labeling in CCAP-Gal4 > UAS-EGFP animals, respectively. Strong overlap of all labels appears as white. The images are maximal projections of volume rendered z-stacks of confocal sections taken through the entire nervous system. Anatomical designations are as follows: SEG, subesophageal ganglia ( $D, M$, and V refer to dorsal, middle, and ventral dispositions of the neurons within the SEG); $\mathrm{T} 1-\mathrm{T} 3$, thoracic ganglia 1-3, respectively; AG, abdominal ganglion. $\boldsymbol{E}$, Consensus patterns of labeling of each $\mathrm{N}_{\text {CCAP }}$ neuron were established by analyzing 11 CCAP-Gal4 > UAS-EGFP preparations double labeled with both anti-bursicon subunit antibodies. The intensity (I) of labeling was scored as described in Materials and Methods following a scale of 0 (no labeling) to 3 (intense labeling), and the frequency $(\nu)$ of labeling of each neuron was determined, with values of $0-3$ indicating that a given neuron was labeled in $0,<33,33-67$, and $>67 \%$ of the preparations. The $\mathrm{N}_{\text {CCAP }}$ neurons in the abdominal ganglion are shown in lateral and medial columns to indicate the generally observed presence of two pairs of CCAP-expressing neurons in each segment, but we have intentionally omitted labels because of ambiguities in assigning anatomical positions to some of these neurons. Segmental identities of the labeled neurons could typically be established unambiguously for A1-A4, but the identities of presumptive $A 5-A 8$ neurons were often not resolved. Also, although neurons were generally paired (with only 1 neuron in each pair immunopositive for the bursicon subunits), the relative positions of the neurons in a pair with respect to the midline varied considerably. For simplicity, we have idealized this pattern by labeling the neurons of the lateral column, without intending to denote anatomical position. Some preparations analyzed had two copies of the CCAP-Gal4 driver. These preparations differed only in labeling two additional midline neurons (asterisk in D). Because all crosses to UAS-effector transgenes used a single copy of CCAP-Gal4, these neurons were omitted from the consensus pattern.

incrementally suppress excitability by varying dosage of the transgene, was expressed at one $(1 \times \mathrm{EKO})$, two $(2 \times \mathrm{EKO})$, and three $(3 \times \mathrm{EKO})$ copy numbers. As an index of bursicon secretion, we measured the effects of these manipulations on wing expansion and cuticle tanning. 


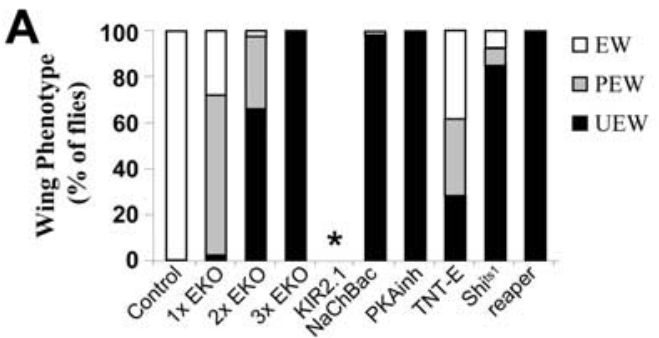

B

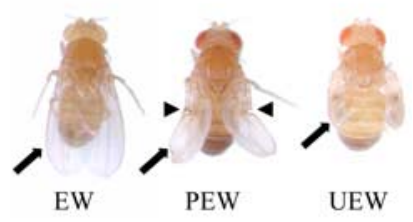

$\mathbf{E}$

C

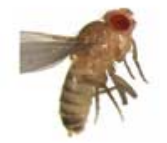

Control

$\mathbf{F}$

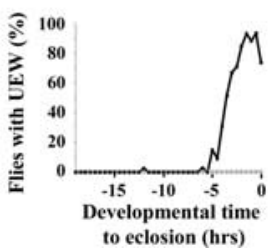

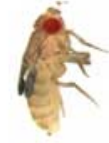

$2 \times$ EKO
D

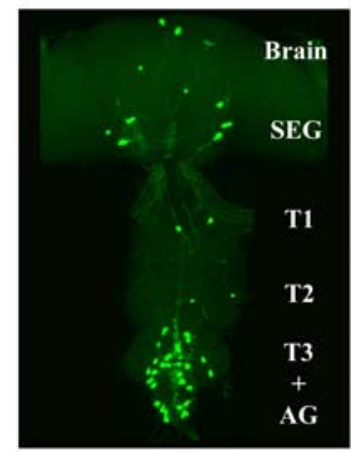

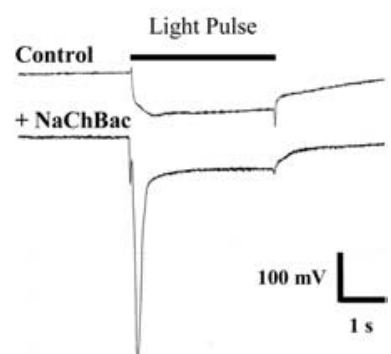

Figure 2. Suppression or enhancement of neuronal function in CCAP-expressing neurons blocks tanning and wing expansion. $A$, Bar graph showing the frequency of wing expansion deficits in the progeny of representative crosses between parental UAS-effector lines and the CCAP-Gal4 driver line. Progeny were heterozygous for the chromosomes bearing effector and driver transgenes, but, in the case of the EKO suppressor, up to three copies of the transgene were introduced by using chromosomes with multiple inserts and/or multiple chromosomes as described in Materials and Methods. The UAS-effector lines were designed to suppress excitability (EKO and Kir2.1), synaptic transmission (TNT and Shi ${ }^{\text {ts1 }}$ ), PKA activity (PKA ${ }^{\text {inh }}$ ), and cell viability (reaper), or to enhance excitability ( $\mathrm{NaChBac}$ ). Animals in all cases except the crosses to UAS-Shi ${ }^{\text {ts } 1}$ were examined at least $24 \mathrm{~h}$ after eclosion, and wings were scored according to the criteria described in Materials and Methods as unexpanded (UEW, black), partially expanded (PEW, gray), or expanded (EW, white). An asterisk indicates that the cross was developmentally lethal, yielding $\leq 1 \%$ viable adult progeny. Flies expressing UAS-Shi ${ }^{\mathrm{ts} 1}$ in $\mathrm{N}_{\text {CCAP }}$ were raised at $18^{\circ} \mathrm{C}$, isolated within 5 min of eclosion, and transferred to the restrictive temperature $\left(34^{\circ} \mathrm{C}\right)$ for $1 \mathrm{~h}$ before being placed back at $18^{\circ} \mathrm{C}$ for at least $48 \mathrm{~h}$ before scoring. $\boldsymbol{B}$, Examples of the wing phenotypes seen in crosses using EKO; designations are as in $\boldsymbol{A}$. Arrows indicate the wings; arrowheads show the unfolded costal elbow, typical of the PEW phenotype. C, Photograph taken $3 \mathrm{~h}$ after eclosion of age-matched, CCAP-Gal4 (left; crossed to (anton-S), or CCAP-Gal4 $>2 \times$ UAS-EKO flies (right) shows the characteristic inhibition of cuticle tanning in animals with $\mathrm{N}_{\text {CCAP }}$ suppression. $\boldsymbol{D}$, Fluorescence micrograph of the excised nervous system of a pharate adult expressing $3 \times$ EKO under CCAP-Gal4. The intrinsic GFP fluorescence of the EKO channel shows that the CCAP-expressing neurons are still present. $\boldsymbol{E}$, Electroretinograms from control animals (top) in response to a $4 \mathrm{~s}$ light stimulus compared with that of animals expressing $\mathrm{NaChBac-EGFP}$ in photoreceptors using the GMR-Gal4 driver (bottom). Photoreceptor depolarization in NaChBac-EGFPexpressing animals results in a strong, inactivating negative potential not seen in control animals, as expected for $\mathrm{NaChBac}-$ mediated currents. $\boldsymbol{F}$, Experimental (CCAP-Gal4 $>$ UAS-Shi ${ }^{\text {ts } 1}$ ) and control flies lacking the driver were raised at $18^{\circ} \mathrm{C}$ and subjected to 1 -h-long temperature jumps to $34^{\circ} \mathrm{C}$ at variable times before eclosion. Flies were returned to $18^{\circ} \mathrm{C}$ after the temperature jump and allowed to eclose and develop for at least $48 \mathrm{~h}$ before scoring the wing phenotype. The graph shows the frequency of unexpanded wing flies for each time point, taken as the time of onset of the temperature jump. Because development is typically observed at $25^{\circ} \mathrm{C}$, the actual times (in hours at $18^{\circ} \mathrm{C}$ ) were divided in half to obtain "Developmental time" at $25^{\circ} \mathrm{C}$.

Expression of increasing copy numbers of the EKO transgene resulted in incremental increases in the frequency and severity of wing expansion deficits. Most flies expressing $1 \times$ EKO partially expanded their wings (Fig. $2 A, B$, PEW) whereas all flies expressing $3 \times$ EKO had unexpanded wings (Fig. $2 A, B$, UEW). The graded changes in wing phenotype suggest that inhibition of bursicon secretion is also graded, depending on EKO transgene dosage.

Consistent with the suppression of bursicon release into the hemolymph, animals exhibiting wing expansion deficits also appeared to melanize very slowly, sometimes over the course of days rather than hours. As shown in Figure $2 C$, flies expressing $2 \times$ EKO typically lack the level of pigmentation seen in age-matched controls $3 \mathrm{~h}$ after eclosion. Inhibition of melanization in these flies appeared complete, with the differences in cuticle pigmen- tation between EKO-expressing and control flies comparable with those between newly eclosed and 3-h-old wild-type flies (Table 1).

A small number of animals expressing $3 \times$ EKO died with head eversion defects and foreshortened wings and legs (data not shown), a phenotype described previously for animals expressing the cell death gene reaper in $\mathrm{N}_{\mathrm{CCAP}}$ (Park et al., 2003). This phenotype was the dominant phenotype seen with Kir2.1, with $<1 \%$ ( 1 of 371 ) of animals expressing this channel in $\mathrm{N}_{\mathrm{C}^{-}}$ CAP surviving to adulthood. Kir2.1 thus appears to be a more effective suppressor of $\mathrm{N}_{\mathrm{CCAP}}$ function than reaper, which had a pupal mortality rate of $79 \%$ ( 283 of 357 animals) in parallel crosses. The survival of adults expressing reaper likely results from incomplete killing of $\mathrm{N}_{\mathrm{CCAP}}$ neurons in some animals, as reported previously by Park et al. (2003). However, we observed no loss of $\mathrm{N}_{\mathrm{CCAP}}$ neurons in pharate adults expressing $3 \times \mathrm{EKO}$ (Fig. $2 \mathrm{D}$ ), indicating that the wing expansion and tanning deficits seen in these animals derive from suppression, rather than the death, of the EKO-expressing neurons. The results thus support a role for excitability in secretion of bursicon. They also underscore the utility of $\mathrm{EKO}$ for manipulating $\mathrm{N}_{\mathrm{CCAP}}$ function. Unlike Kir2.1, which appears to suppress excitability much more potently, EKO achieves suppression sufficient to generate adult deficits, without incurring developmental lethality.

\section{Enhancement of excitability of $\mathrm{N}_{\mathrm{CCAP}}$ also inhibits wing expansion and tanning}

The effects of EKO are consistent with recent observations by Hodge et al. (2005), who observed wing expansion deficits in $\sim 70 \%$ of flies overexpressing the Shaw $\mathrm{K}^{+}$ channel in $\mathrm{N}_{\text {CCAP. }}$. Shaw, which is endogenously expressed in $\mathrm{N}_{\mathrm{CCAP}}$, is thought to contribute to the resting leak conductance of cells that express it and should serve to suppress excitability. Interestingly, Hodge et al. (2005) found that inhibition of Shaw expression in $\mathrm{N}_{\mathrm{CCAP}}$ by dominant-negative techniques also resulted in wing expansion deficits in $20-55 \%$ animals, depending on sex. This manipulation suggests that enhancement of excitability in $\mathrm{N}_{\mathrm{CCAP}}$ may disrupt bursicon release also. To further test this possibility, we made transgenic flies containing a UAS-transgene for the voltage-activated, bacterial sodium channel $\mathrm{NaChBac}$ to perform targeted enhancement of excitability. The NaChBac gene was fused to the gene for EGFP so that expression and localization of the expressed construct (NaChBac-EGFP) could be monitored.

We first showed that the NaChBac-EGFP construct enhances excitability in Drosophila neurons by expressing it in photoreceptors using the GMR-Gal4 driver (Fig. 2E). ERGs from NaChBacEGFP-expressing animals exhibited large, slowly activating and 
Table 1. Tanning deficits in animals with altered $\mathrm{N}_{\text {CCAP }}$ function

\begin{tabular}{|c|c|c|c|c|}
\hline & EKO & TNT-E & $\mathrm{NaChBac}$ & PKA $^{\text {inh }}$ \\
\hline AP-Gal4 & $25 \pm 2(n=25)$ & $19 \pm 2(n=7)$ & $22 \pm 4(n=9)$ & $20 \pm 3(n=13)$ \\
\hline C929-Gal4 & $17 \pm 5(n=9)$ & $4 \pm 2(n=36)$ & $-1 \pm 2(n=10)$ & $3 \pm 2(n=18)$ \\
\hline
\end{tabular}

Cuticle tanning was evaluated in experimental animals expressing the indicated suppressors of neuronal function under the control of either (CAP-Gal4 or C929-Gal4. Experimental animals were photographed $3 \mathrm{~h}$ after eclosion as shown in Figure 2 C together with age-matched controls not expressing the UAS-effector. Tanning difference scores were calculated as described in Materials and Methods by determining the average (grayscale) pixel intensity of thoracic cuticle on experimental and control flies and calculating the difference. A larger value indicates less tanning in the experimental fly relative to the control. For comparison, the tanning difference score for newly eclosed Canton-S adults relative to 3 -h-old animals was $24 \pm 2(n=36)$. SEMs are indicated. Animals expressing $2 \times$ EKO were scored for the CCAP-Gal 4 crosses, whereas animals expressing $3 \times$ EKO were scored for the 929 -Gal 4 crosses.

inactivating depolarizations that were absent in the ERGs of control animals, consistent with the properties described previously for $\mathrm{NaChBac}$ expressed in Xenopus oocytes (Ren et al., 2001). When expressed in $\mathrm{N}_{\mathrm{CCAP}}$, $\mathrm{NaChBac}-\mathrm{EGFP}$ caused complete failure of wing expansion (Fig. $2 \mathrm{~A}$ ) and inhibited tanning at levels comparable with $2 \times \mathrm{EKO}$ (Table 1). These effects were not accompanied by pupal mortality (data not shown). Control crosses lacking either CCAP-Gal4 or UAS-NaChBac-EGFP had no effect on either wing expansion or tanning (data not shown). These results indicate that making neurons within $\mathrm{N}_{\mathrm{CCAP}}$ hyperexcitable also disrupts bursicon release, perhaps by rendering it constitutive or otherwise altering its timing.

\section{PKA activity and synaptic transmission within $\mathrm{N}_{\mathrm{CCAP}}$ also are required for wing expansion and tanning}

To determine whether bursicon release is likely to require PKA activity in $\mathrm{N}_{\mathrm{CCAP}}$, we expressed a dominant-negative form of the PKA regulatory subunit (UAS-PKA ${ }^{\text {inh }}$ ) that does not bind cAMP (Li et al., 1995). Expression of UAS-PKA ${ }^{\text {inh }}$ with CCAP-Gal4 completely inhibited both wing expansion (Fig. 2A) and tanning (Table 1), whereas expression of a control construct (PKA ${ }^{\text {inh-m }}$ ), identical to $\mathrm{PKA}^{\text {inh }}$ but lacking binding sites for the catalytic subunit of PKA (Rodan et al., 2002), yielded 100\% of flies with expanded wings (data not shown). These results indicate that PKA activity in $\mathrm{N}_{\mathrm{CCAP}}$ is required for normal bursicon release. In contrast, PKA activity in $\mathrm{N}_{\mathrm{CCAP}}$ is unlikely to be required for head eversion, because CCAP-Gal $>>\mathrm{PKA}^{\text {inh }}$ flies suffered no pupal mortality (data not shown).

We also investigated whether synaptic transmission within $\mathrm{N}_{\mathrm{CCAP}}$ might be required for bursicon release. Targeted suppression of neurotransmission is commonly accomplished with one of two tools: tetanus-toxin light chain (UAS-TNT), which blocks neurotransmitter release by cleaving the protein synaptobrevin, and Shibire-ts ${ }^{1} \quad\left(\mathrm{UAS}-\mathrm{Shi}^{\mathrm{ts}}{ }^{1}\right)$, a temperature-sensitive, dominant-negative form of the protein dynamin, which is required for reuptake of neurotransmitter. The temperature sensitivity of Shi ${ }^{\text {ts } 1}$ allows dynamin function to be acutely inhibited by shifting flies to the restricted temperature. Park et al. (2003) have reported previously that expression of UAS-Shi ${ }^{\text {ts } 1}$ within $\mathrm{N}_{\mathrm{CCAP}}$ yields flies with the juvenile phenotype. However, because suppression of dynamin function in these experiments was constitutive rather than acute, with flies raised at the restricted temperature, the observed phenotypes may have derived from pleiotropic developmental defects distinct from suppression of synaptic transmission (Kitamoto, 2001).

To further examine the role of synaptic transmission in bursicon release, we constitutively expressed TNT in $\mathrm{N}_{\text {CCAP. }}$. Using UAS-Shi ${ }^{\text {ts } 1}$, we also acutely suppressed synaptic activity within $\mathrm{N}_{\mathrm{CCAP}}$ for $1 \mathrm{~h}$ after eclosion, the time window during which bursicon secretion into the hemolymph peaks in blowflies (Cottrell, 1962a; Fraenkel and Hsiao, 1965). Expression of TNT in
$\mathrm{N}_{\text {CCAP }}$ resulted in wing expansion deficits in approximately twothirds of animals, with one-third completely failing to expand their wings (Fig. 2 B). Expression of an inactive form of TNT had no effect on wing expansion (data not shown). CCAPGal4 $>$ UAS-TNT flies assayed for tanning were also poorly melanized (Table 1). However, in the tanning assay, all but one of the flies had unexpanded wings. It is likely that conditions of the tanning assay inhibited wing expansion, although it remains possible that wing expansion was generally delayed in CCAPGal4>UAS-TNT-E flies.

We observed stronger effects on wing expansion in crosses of CCAP-Gal4 to UAS-Shi ${ }^{\text {ts } 1}$. Animals bearing the UAS-Shi ${ }^{\text {ts }}$ transgene in the presence or absence of the CCAP-Gal4 driver were raised at $18^{\circ} \mathrm{C}$ and shifted to $34^{\circ} \mathrm{C}$ within 5 min after eclosion for $1 \mathrm{~h}$. Ninety-three percent of the newly eclosed adults expressing UAS-Shi ${ }^{\text {tsl }}$ in $\mathrm{N}_{\mathrm{CCAP}}$ failed to completely expand their wings under this condition (Fig. 2A), whereas all of the control animals lacking CCAP-Gal4 expanded their wings normally (data not shown). This result strongly implied that synaptic transmission within $\mathrm{N}_{\mathrm{CCAP}}$ is required for bursicon release.

To determine whether synaptic communication before eclosion also was necessary for subsequent bursicon secretion, we used UAS-Shi ${ }^{\text {ts } 1}$ to acutely block neurotransmission in $\mathrm{N}_{\text {CCAP }}$ for $1 \mathrm{~h}$ increments during the $19 \mathrm{~h}$ preceding eclosion. These experiments revealed a window of sensitivity to synaptic suppression that extended $\sim 5 \mathrm{~h}$ before eclosion. There thus appears to be an extended period during which $\mathrm{N}_{\mathrm{CCAP}}$ activity is required to ensure later release of bursicon (Fig. $2 F$ ), although we cannot rule out the possibility that the extended time course represents a lasting effect of dynamin downregulation.

\section{The c929-Gal4 enhancer-trap line defines a subset of bursicon-expressing neurons within $\mathrm{N}_{\text {CCAP }}$}

Based on our finding that synaptic communication within $\mathrm{N}_{\text {CCAP }}$ is required for wing expansion, we hypothesized that bursicon secretion might be modulated by neurons within $\mathrm{N}_{\text {CCAP }}$ that did not themselves make the hormone. To test this possibility required Gal4 driver lines that expressed selectively in subsets of $\mathrm{N}_{\text {CCAP }}$ neurons. To identify such lines, we took advantage of the ability of the EKO channel to disrupt the bursicon pathway without causing developmental lethality. We screened $\sim 120 \mathrm{Gal} 4$ enhancer-trap lines and identified several that yielded animals with wing expansion deficits when expressing $2 \times$ EKO. Among these was c929-Gal4, which has been reported previously to express broadly in peptidergic neurons, including some that express CCAP (Hewes et al., 2003). Examination of the expression pattern of $\mathrm{c} 929-\mathrm{Gal} 4$ revealed that, within $\mathrm{N}_{\mathrm{CCAP}}$, it was primarily selective for bursicon-expressing cells in the pharate adult. We refer to the subset of $\mathrm{N}_{\mathrm{CCAP}}$ that lies within the c929-Gal4 expression pattern as $\mathrm{N}_{\mathrm{CCAP}}-\mathrm{C} 929$.

The coincidence of both CCAP and bursicon immunoreactivity with the c929-Gal4 pattern is shown in Figure 3. Nervous systems from c929-Gal4>UAS-EGFP animals were labeled with anti-CCAP (Fig. $3 A, D, F$ ) and anti-burs $\beta$ (Fig. $3 B, E, F$ ) antibodies. Extensive overlap is particularly evident within the abdominal ganglion (Fig. $3 D-F$ ) in which the $\mathrm{B}_{\mathrm{AG}}$ typically coexpressed EGFP. This is more clearly seen in a preparation labeled with the anti-burs $\alpha$ antibody in the absence of anti-CCAP staining (Fig. $3 G-I)$. The consensus labeling pattern of c929-Gal4 within $\mathrm{N}_{\text {CCAP }}$ (Fig. 4, left) and the consensus expression of bursicon within this pattern (Fig. 4, right) shows that, of the $18 \mathrm{~N}_{\text {CCAP }}$ neurons robustly labeled by c929-Gal4 $>$ UAS-EGFP, 14 of these are the strongly bursicon-expressing $\mathrm{B}_{\mathrm{AG}}$. 

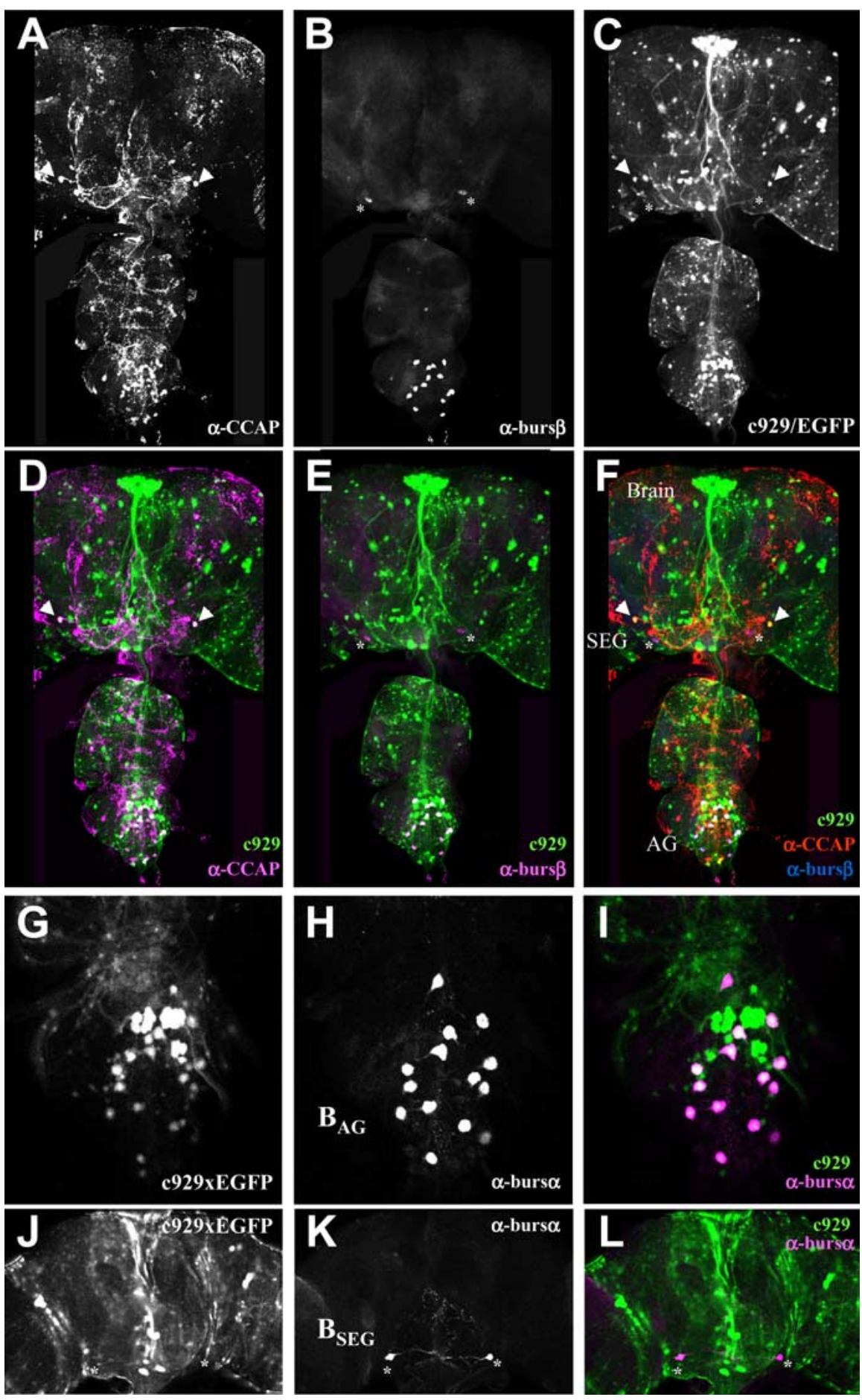

Figure 3. The expression pattern of the (929-Gal4 enhancer-trap line includes most bursicon-expressing neurons of $\mathrm{N}_{\text {CCAP. }}$. $\boldsymbol{A}-\boldsymbol{F}$, The excised CNS of a pharate adult expressing UAS-EGFP in the (929-Gal4 expression pattern was double labeled with antibodies to CCAP $(\boldsymbol{A}, \boldsymbol{D}$, magenta) and bursicon $\beta$-subunit ( $\boldsymbol{B}, \boldsymbol{E}$, magenta). The 929 -Gal4 $>$ UAS-EGFP pattern $(\boldsymbol{C})$ is overlaid for each antibody $(\boldsymbol{D}, \boldsymbol{E}$, green) to show double-labeled cells, which appear as white, as do triple-labeled cells in the merged image $(\boldsymbol{F})$. All bursicon-positive $\mathrm{N}_{\text {CCAP }}$ cells in the abdominal (AG) and thoracic (T3) ganglia were within the c929-Gal4 expression pattern. Two cells outside the (929-Gal4 pattern in the SEG also expressed bursicon (asterisks, $\boldsymbol{E}-\boldsymbol{G}$ ). This pair presumably corresponds to the normally CCAP-positive neurons of the ventral SEG (compare with Fig. 1E), but intriguingly these cells do not express CCAP in C929-Gal4 animals. Arrowheads $(\boldsymbol{D}, \boldsymbol{F})$ indicate a pair of CCAP-positive neurons that are also consistently in the c929-Gal4 pattern but that do not express bursicon. Images are volume-rendered confocal z-stacks as in Figure 1. G-I, Single confocal sections through the abdominal $(\mathbf{G}-\boldsymbol{I})$ or subesophageal $(\boldsymbol{J}-\boldsymbol{L})$ ganglion of a $\mathbf{c} 929-\mathrm{Gal} 4>$ UAS-EGFP animal double labeled with antibodies to the bursicon $\alpha$-subunit. The overlap of $(929-G a l 4$ driven $\operatorname{EGFP}(\boldsymbol{G}, \boldsymbol{J})$ and bursicon $(\boldsymbol{H}, \boldsymbol{K})$ is evident in the merged images $(\boldsymbol{I}, \boldsymbol{L})$ in which EGFP appears as green, bursicon as magenta, and double labeling as white. The $B_{A G}$ and $B_{S E G}$ (asterisks) are as indicated.
The two bursicon-expressing neurons not within $\mathrm{N}_{\mathrm{CCAP}}$-c929 were located in the ventral portion of the subesophageal ganglion (Fig. 3 E, F, asterisks). The absence of coincident labeling in these neurons is further illustrated in a c929-Gal4>UASEGFP preparation labeled only for the bursicon $\alpha$-subunit in Figure 3J-L. We presume that these neurons correspond to the $\mathrm{N}_{\text {CCAP }}$ neurons of ventral SEG previously designated $\mathrm{B}_{\mathrm{SEG}}$ (compare with Fig. $1 E$ ), despite their lack of associated CCAP immunoreactivity. This is because we found no CCAP-immunopositive neurons in the position of the $\mathrm{B}_{\mathrm{SEG}}$ (compare with Fig. $1 E$ ) in $4929-G a l 4>$ UAS-EGFP animals. We also observed that the laterally disposed pair of CCAP-positive neurons in the mid-subesophageal ganglion (Fig. 3A,D,F arrowheads), which expressed bursicon at moderate intensity and frequency in CCAP-Gal4 $>$ UASEGFP-expressing animals (Fig. 1E), did not express bursicon in c929-Gal4 $>$ UASEGFP animals, although they were within

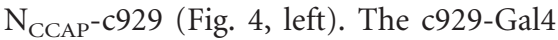
transgene inserts into a genomic region that regulates expression of the dimmed transcription factor, which is important for establishing the functional identity of neurosecretory cells (Hewes et al., 2003). It is possible that changes in dimmed expression in the c929-Gal4 line alter the patterns of CCAP and bursicon expression in the brain and SEG.

Manipulation of neuronal function with c929-Gal4 distinguishes distinct functional groups within $\mathrm{N}_{\text {CCAP }}$ To determine which manipulations of $\mathrm{N}_{\text {CCAP }}$ function were likely to exert their effects on tanning and wing expansion by acting directly on the bursicon-expressing neurons of the abdominal ganglia, we crossed c929-Gal4 flies to flies from the various UAS-effector lines tested previously (Fig. 5, top). As with CCAP-Gal4, suppression of excitability by EKO incrementally increased wing expansion deficits with increasing transgene copy numbers, with expression of $3 \times \mathrm{EKO}$ resulting in unexpanded wings in 100\% of animals and failure to tan (Table 1). At all copy numbers of EKO, the percentage of animals with wing expansion deficits was similar to that seen with CCAP-Gal4, indicating that effector gene expression by c929-Gal4 matched that driven by CCAP-Gal4 in the functionally relevant cells.

To confirm that the deficits seen in EKO-expressing flies resulted from suppression of excitability in $\mathrm{N}_{\text {CCAP }}$ rather than in some other group of neurons in the 
c929-Gal4 expression pattern, we made CCAP-Gal80 transgenic flies that expressed the Gal4 inhibitor, Gal80, selectively in $\mathrm{N}_{\mathrm{CCAP}}$ (supplemental Fig. 1, available at www.jneurosci.org as supplemental material). Presence of the CCAP-Gal80 transgene in c929-Gal4>UAS-EKO flies completely relieved the inhibition of wing expansion by EKO (Fig. 5, bottom), demonstrating that this effect derived specifically from the suppression of excitability within $\mathrm{N}_{\mathrm{CCAP}}$ (i.e., within $\mathrm{N}_{\mathrm{CCAP}}$-c929). In contrast, Kir2.1 expression in the c929Gal4 pattern was lethal, an effect that was not blocked by coexpression of CCAPGal80. Lethality occurred early in larval development (data not shown) and was likely attributable to suppression of ecdysis triggering hormone release by the tracheal-associated Inka cells (Park et al., 2002), which are also included in the c929Gal4 pattern (O'Brien and Taghert, 1998), although additional observation would be required to verify the cause of death.

More importantly, all manipulations of neuronal function made with c929-Gal4 besides the suppression of excitability were without effect (Fig. 5, top). Neither enhancement of excitability by $\mathrm{NaChBac}$ -

EGFP nor inhibition of PKA activity by PKA $^{\text {inh }}$ had a significant effect on wing expansion when expressed in the c929-Gal4 pattern and correspondingly little effect on cuticle tanning (Table 1). Similarly, suppression of neurotransmission, either by TNT or acutely after eclosion by UAS-Shi ${ }^{\text {tsl }}$, caused complete wing expansion failure in $<1 \%$ of animals. These results indicate that the previously observed effects of these manipulations on bursicon secretion, when applied to all $\mathrm{N}_{\mathrm{CCAP}}$, must derive, at least in part, from their effects on neurons outside of $\mathrm{N}_{\mathrm{CCAP}}-\mathrm{C} 929$.

Suppression of excitability with both CCAP-Gal4 and c929Gal4 blocks bursicon secretion into the hemolymph

As noted above, the wing expansion and tanning deficits resulting from manipulation of $\mathrm{N}_{\mathrm{CCAP}}$ and $\mathrm{N}_{\mathrm{CCAP}}-\mathrm{c} 929$ function are consistent with impairment of bursicon release after eclosion. To confirm directly that bursicon secretion is impaired in animals with compromised neuronal function, we assayed hemolymph samples from control and experimental animals for the presence of bursicon by Western blot (Fig. 6). Bursicon bioactivity in the hemolymph of both blowflies and hawkmoths has been shown previously to peak within $1 \mathrm{~h}$ of emergence (Fraenkel and Hsiao, 1965; Reynolds et al., 1979). We therefore collected $0.5 \mu \mathrm{l} \mathrm{sam-}$ ples of hemolymph within $1 \mathrm{~h}$ of eclosion from animals expressing $3 \times \mathrm{EKO}, \mathrm{PKA}^{\mathrm{inh}}$, NaChBac-EGFP, or nothing (driver only) under the control of CCAP-Gal4. Hemolymph samples collected from control animals displayed an immunoreactive band at the size expected for the bursicon $\alpha$-subunit $(\sim 16 \mathrm{kDa})$. In contrast, the hemolymph collected from animals in which either excitability or PKA activity was impaired lacked bursicon immunoreactivity, consistent with the failure of these animals to tan or expand their wings.

Similarly, hemolymph samples from animals expressing $3 \times$ EKO in the c929-Gal4 pattern lacked a bursicon-immunoreactive band, whereas bursicon was present in hemolymph from animals

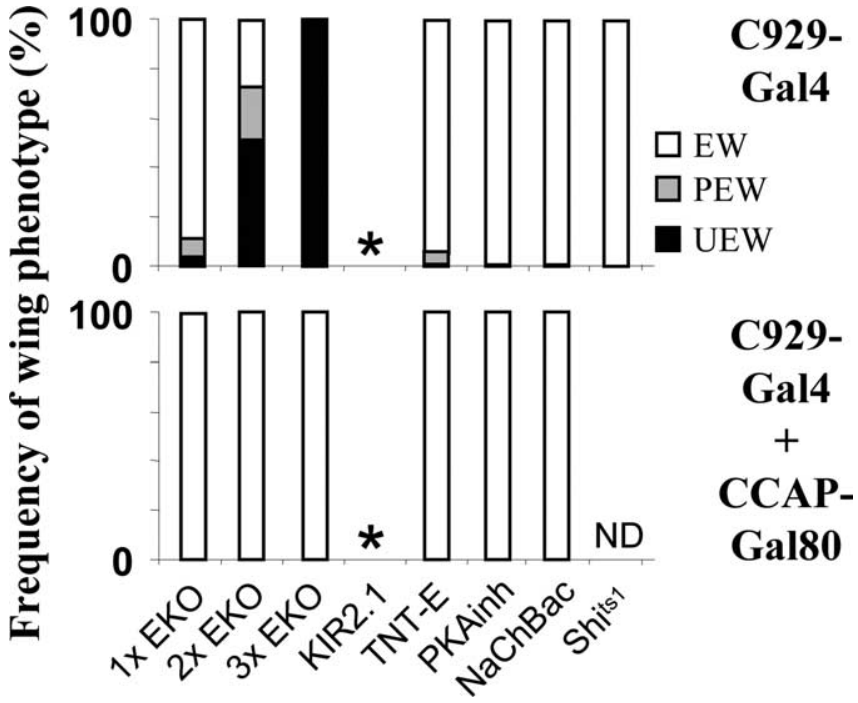

Figure 5. Suppression of excitability in the $\mathrm{N}_{\text {CCAP }}$ component of the $\mathrm{C} 929-\mathrm{Ga} 14$ pattern blocks wing expansion. The $929-\mathrm{Gal} 4$ driver was used to express the suppressors and enhancers of activity with (bottom) or without (top) coexpression of Gal 80 in $\mathrm{N}_{\text {CCAP }}$ as described in Materials and Methods. The frequencies of wing phenotypes in the progeny of the crosses are represented as in Figure $2 A$. Progeny from the $\mathrm{C} 929-\mathrm{Gal} 4>\mathrm{UAS}_{\mathrm{S}} \mathrm{Shi}{ }^{\mathrm{t} 1} \mathrm{Cross}$ were raised at $18^{\circ} \mathrm{C}$ and transferred to $34^{\circ} \mathrm{C}$ immediately after eclosion for $1 \mathrm{~h}$ before being returned to $18^{\circ} \mathrm{C}$. Only suppression of excitability by EKO caused wing expansion deficits, an effect that was clearly exerted by suppression of neurons within $\mathrm{N}_{\text {CCAP. }}$.

expressing PKA ${ }^{\text {inh }}$ and NaChBac-EGFP (Fig. 6), albeit at lower titers than those observed in controls. Enhancement of excitability and suppression of PKA in $\mathrm{N}_{\mathrm{CCAP}}$ - 9929 thus appears to reduce, but not to eliminate, bursicon secretion into the hemolymph. Previous work in blowflies has shown that hemolymph can be diluted $\sim 100$-fold without loss of tanning activity (Fraen- 


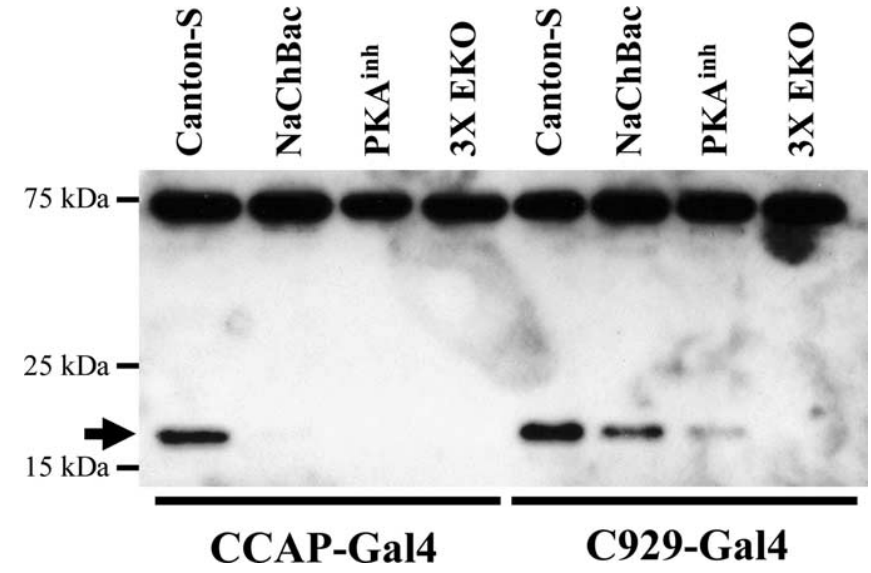

Figure 6. Suppression of excitability with both CCAP-Gal4 and $929-G a l 4$ blocks bursicon secretion into the hemolymph. Western blots of hemolymph extracted from flies in which

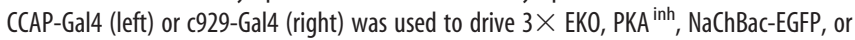
nothing (Canton-S) probed with antibodies to the bursicon $\alpha$-subunit. The positions of selected molecular weight markers are shown. The bursicon $\alpha$-subunit runs at $\sim 16 \mathrm{kDa}$ (arrow). The $\sim 75 \mathrm{kDa}$ band of unknown identity (see Results) serves as a useful control for the amount of sample loaded.

kel and Hsiao, 1965), indicating that bursicon is released in excess. Our results support this conclusion and indicate that wing expansion is similarly unimpaired by substantially lowered hemolymph titers of bursicon. In general, our results with both the CCAP-Gal4 and c929-Gal4 drivers demonstrate that the presence of bursicon in the hemolymph correlates with successful wing expansion and tanning, and its absence correlates with a failure to tan and expand wings. The identity of the highly immunoreactive band at $75 \mathrm{kDa}$ in our Western blots is not known, but it is unlikely to be bursicon because it is also present on Western blots of tissue from the putative bursicon null mutant burs ${ }^{\mathrm{Z} 4410}$ (data not shown).

\section{$\mathrm{NaChBac}$ depletes bursicon from neuronal processes in the CNS}

The absence of bursicon immunoreactivity in the hemolymph of CCAP-Gal4 animals expressing NaChBac-EGFP is consistent with the failure of wing expansion in these animals, but it is surprising insofar as enhancement of excitability in these neurons appears to inhibit bursicon release, just as suppression of excitability does. It is possible that $\mathrm{NaChBac-EGFP} \mathrm{constitutively} \mathrm{ac-}$ tivates inhibitory inputs onto the $\mathrm{B}_{\mathrm{AG}}$ or that it critically disrupts signaling in the $\mathrm{N}_{\mathrm{CCAP}}$ network so that bursicon release from the $\mathrm{B}_{\mathrm{AG}}$ is no longer properly regulated. Alternatively, NaChBacEGFP expression may deplete bursicon by causing constitutive release of the hormone. Our results predict that $\mathrm{NaChBac-EGFP}$ expression in $\mathrm{N}_{\mathrm{CCAP}}$, and not in $\mathrm{N}_{\mathrm{CCAP}}-\mathrm{c} 929$, should cause depletion, if it occurs. To test this prediction, we immunostained the nervous systems of animals expressing $\mathrm{NaChBac}$-EGFP in either $\mathrm{N}_{\mathrm{CCAP}}$ (Fig. $7 B$ ) or $\mathrm{N}_{\mathrm{CCAP}}$-c929 (Fig. 7F) with anti-burs $\alpha$ antibodies and compared them with similarly stained nervous systems from control animals (Fig. $7 A, E$, respectively) and animals expressing $3 \times$ EKO and PKA ${ }^{\text {inh }}$ (Fig. $7 C, D$ and $G, H$, respectively). We immunolabeled multiple preparations in parallel for each condition and scored blind the fluorescence of bursiconimmunopositive processes of the brain and the subesophageal, thoracic, and abdominal ganglia. We were unable to compare the levels of immunoreactivity in the nerves exiting the abdominal ganglion because of the difficulty in consistently preserving the integrity of these structures.

We observed overtly diminished bursicon immunoreactivity in the processes of animals expressing $\mathrm{NaChBac-EGFP}$ in $\mathrm{N}_{\text {CCAP }}$ (Fig. 7, compare process labeling within the thoracic ganglia shown in $B$ with that shown in $A, C, D)$. A nonparametric Kruskal-Wallis test of the average bursicon staining in all preparations indicated a significant difference $(p<0.001)$ in the distribution of these scores, and post hoc comparisons indicated that the difference was attributable to lower average staining seen in $\mathrm{NaChBac-EGFP-expressing} \mathrm{animals} \mathrm{(Fig.} \mathrm{7I).} \mathrm{In} \mathrm{contrast,} \mathrm{we}$ found no significant differences in bursicon immunoreactivity in the neuronal processes of preparations expressing $\mathrm{NaChBac}-$ EGFP in $\mathrm{N}_{\mathrm{CCAP}}$-c929 when compared with controls (Fig. $7 E-$ $H, J)$. These results indicate that NaChBac-EGFP induces depletion of bursicon, at least in the CNS, because of enhancement of excitability in $\mathrm{N}_{\mathrm{CCAP}}-\mathrm{R}$.

\section{Discussion}

$\mathrm{N}_{\text {CCAP }}$ neurons in the abdominal ganglion release bursicon into the hemolymph

Tanning bioassays performed in blowflies and the hawkmoth, Manduca sexta, have determined that bursicon bioactivity is concentrated in the abdominal ganglia from which it is likely to be released into the hemolymph (Fraenkel and Hsiao, 1965; Truman, 1973; Taghert and Truman, 1982a,b). Recent molecular characterization of bursicon, and the availability of antibodies to its two subunits, has allowed identification of neurons that make bursicon in several insects and confirmed previous findings that some of these coexpress CCAP (Honegger et al., 2002), a peptide with cardioacceleratory activity (Tublitz and Evans, 1986; Nichols et al., 1999). In Drosophila larvae, bursicon expression is restricted to a small number of CCAP-expressing neurons in the ventral nerve cord (Honegger et al., 2002; Dewey et al., 2004; Luo et al., 2005). We have now mapped its distribution in late-stage pharate adults, a stage more relevant to its release into the hemolymph. We show that bursicon expression in the adult is broader but remains restricted to $\mathrm{N}_{\mathrm{CCAP}}$, with most bursicon-expressing neurons located in the abdominal ganglion. The 14 abdominal neurons $\left(\mathrm{B}_{\mathrm{AG}}\right)$ are included in the expression pattern of the $\mathrm{c} 929$ Gal4 enhancer-trap line, whereas a pair of neurons that consistently express bursicon in the subesophageal ganglion $\left(\mathrm{B}_{\mathrm{SEG}}\right)$ are not. Although we occasionally observed bursicon immunoreactivity in neurons other than these 16 , the variability of its expression rendered these neurons unlikely substrates for the highly invariant developmental processes of cuticle tanning and wing expansion that bursicon mediates.

We provide functional evidence that the $\mathrm{B}_{\mathrm{AG}}$ are responsible for release of bursicon into the hemolymph by demonstrating that suppression of excitability in the c929-Gal4 pattern blocks bursicon release into the hemolymph. The inhibition of wing expansion by this manipulation suggests that wing expansion, like tanning, also requires bursicon in the hemolymph. This is consistent with a proposed role for bursicon in cuticle plasticization, a process required to render the wing extensible before expansion (Cottrell, 1962b; Reynolds, 1977). The partially expanded wing phenotypes we see at lower levels of suppression may result from incomplete cuticle plasticization attributable to insufficient bursicon in the hemolymph.

The expression of $\mathrm{c} 929-\mathrm{Gal} 4$ in $\mathrm{B}_{\mathrm{AG}}$, but not $\mathrm{B}_{\mathrm{SEG}}$, may indicate functional distinctions between these two groups of neurons. The c929-Gal4 expression pattern has been extensively characterized and conforms primarily to that of dimmed, a gene that neigh- 
bors the Gal4 insertion site and is involved in upregulating peptide processing (Hewes et al., 2003). CCAP has been proposed to promote wing expansion by stimulating heart activity (Tublitz and Truman, 1985), and the coincidence of bursicon and c929-Gal4 expression in $\mathrm{B}_{\mathrm{AG}}$ may reflect upregulation of peptidergic processing in $\mathrm{N}_{\mathrm{CCAP}}$ neurons preparing to corelease both CCAP and bursicon into the hemolymph. $\mathrm{B}_{\mathrm{SEG}}$, which lie outside the c929-Gal4 expression pattern and are unlikely to contribute significantly to circulating levels of bursicon in the hemolymph after eclosion based on our Western blot data, may instead release the hormone within the CNS, in which it may regulate behaviors required for wing expansion (Baker and Truman, 2002).

\section{Enhancement of excitability and bursicon release: mechanisms and regulation}

We introduce here a new tool for the targeted enhancement of cellular excitability and use it to demonstrate that secretion of bursicon from $\mathrm{B}_{\mathrm{AG}}$ must be regulated by a population of $\mathrm{N}_{\text {CCAP }}$ neurons outside of

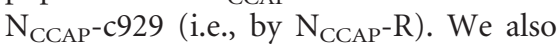
provide evidence that $\mathrm{B}_{\mathrm{AG}}$ are electrically quiescent before eclosion. The tool is a GFP-tagged version of the bacterial sodium channel $\mathrm{NaChBac}$ discovered by Ren et al. (2001). We have made transgenic flies that express UAS-NaChBac-EGFP under the control of Gal4 drivers and show that NaChBac-EGFP enhances photoreceptor excitability. In an accompanying paper (Nitabach et al., 2005), we further demonstrate the utility of the $\mathrm{NaChBac}$ channel in enhancing excitability in other cell types.

Here we show that enhancement of excitability in $\mathrm{N}_{\text {CCAP }}$ using $\mathrm{NaChBac-EGFP}$ eliminates bursicon secretion into the hemolymph and blocks tanning and wing expansion. This observation is consistent with results reported previously by Hodge et al. (2005), who found that dominant-negative inhibition of Shaw $\mathrm{K}^{+}$channel function in $\mathrm{N}_{\mathrm{CCAP}}$ resulted in many animals exhibiting the juvenile phenotype, particularly females. Interestingly, we have observed a similar sexual dimorphism in the effects of $\mathrm{NaChBac}$ in $\mathrm{N}_{\mathrm{CCAP}}$ when using a "weaker" insert that lacks the EGFP tag (data not shown). The Shaw channel is expressed endogenously in $\mathrm{N}_{\mathrm{CCAP}}$, and its properties suggest that it acts to limit membrane excitability. Inhibiting Shaw should therefore enhance excitability like NaChBac-EGFP. Conversely, overexpressing Shaw should suppress excitability and, like EKO, cause tanning and wing expansion deficits, a result also reported by Hodge et al. (2005).

Our observation that bursicon secretion into the hemolymph is relatively unimpaired by expression of $\mathrm{NaChBac}$-EGFP in

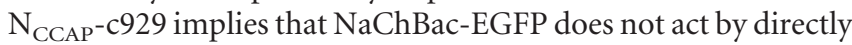
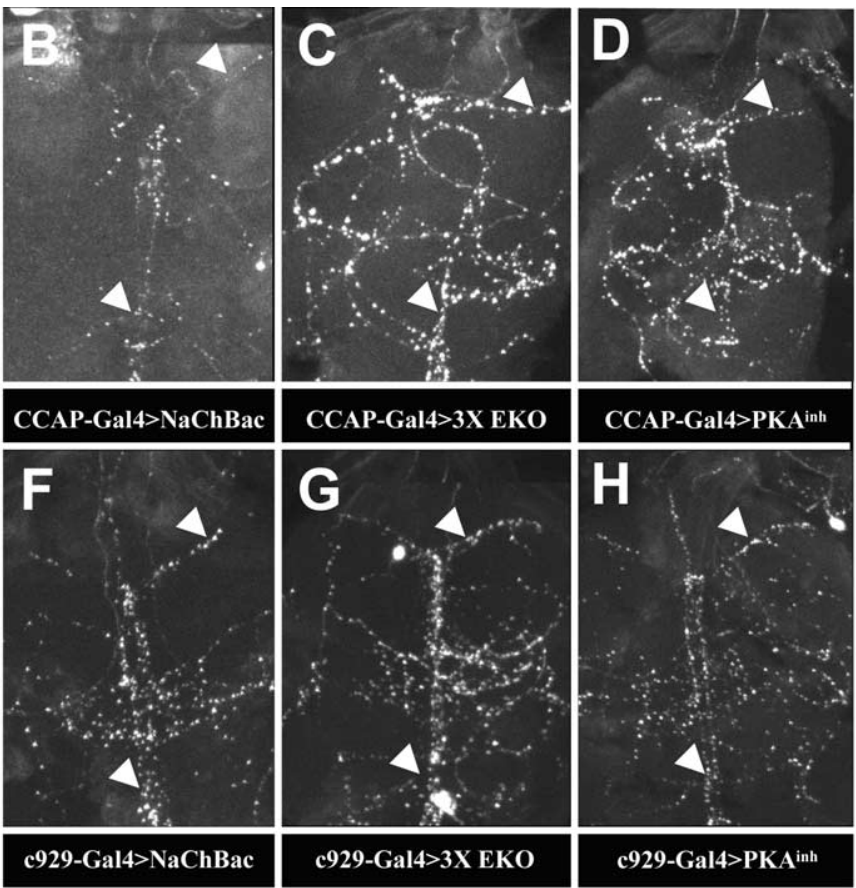

CCAP-Gal4 $>$ PKA ${ }^{\text {inh }}$

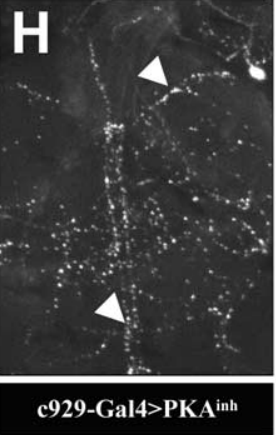

$\mathbf{J}$

c929-Gal4 Crosses

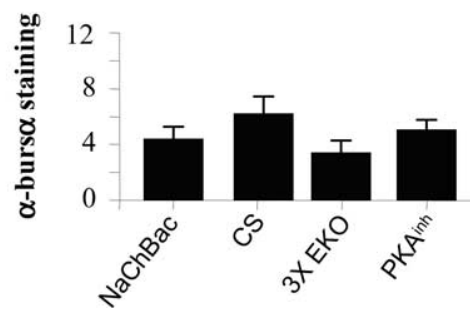

Figure 7. NaChBac-EGFP expression with CCAP-Gal4, but not $\mathrm{C} 929-\mathrm{Gal} 4$, depletes bursicon immunoreactivity in neuronal PKA ${ }^{\text {inh }}(\boldsymbol{D}, \boldsymbol{H})$ in either $\mathrm{N}_{\text {CCAP, }}$ using the CCAP-Gal4 driver $(\boldsymbol{B}-\boldsymbol{D})$, or in the $\mathrm{C} 929-\mathrm{Gal} 4$ pattern $(\boldsymbol{F}-\boldsymbol{H})$. The two arrowheads in each cres of up to seven preparations from each cross was scored blind, as described in Materials and Methods. Average scores from preparations. SEM are indicated.

enhancing the excitability of $\mathrm{B}_{\mathrm{AG}}$. Instead, $\mathrm{NaChBac-EGFP} \mathrm{must}$ alter $B_{A G}$ activity when it is expressed in neurons in $\mathrm{N}_{\mathrm{CCAP}}-\mathrm{R}$. The failure of $\mathrm{NaChBac}-\mathrm{EGFP}$ to affect bursicon release when expressed by c929-Gal4 is unlikely to result from lower transgene expression levels in $\mathrm{B}_{\mathrm{AG}}$ than are obtained with CCAP-Gal4, because both drivers cause similar levels of wing expansion failure when driving expression of varying copy numbers of the EKO transgene.

How enhancement of excitability in $\mathrm{N}_{\mathrm{CCAP}}$ impairs bursicon release remains an open question. Our observation that $\mathrm{NaChBac}-\mathrm{EGFP}$ depletes bursicon immunoreactivity in central processes when expressed in $\mathrm{N}_{\mathrm{CCAP}}-\mathrm{R}$ suggests a constitutive enhancement of bursicon secretion. If the central processes derive from $\mathrm{B}_{\mathrm{SEG}}$, this effect may be a direct consequence of their enhanced excitability. Enhanced excitability in $\mathrm{B}_{\mathrm{AG}}$, by expression of $\mathrm{NaChBac}-\mathrm{EGFP}$ in $\mathrm{N}_{\mathrm{CCAP}}$-c929, does not deplete central bur- 
A

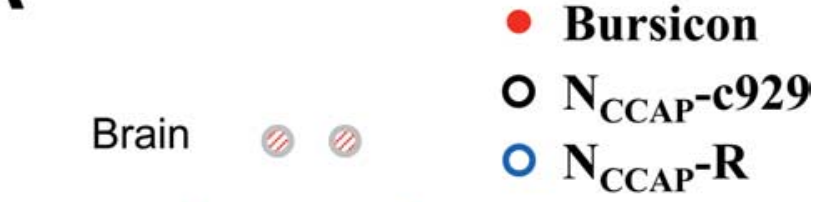

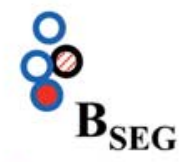

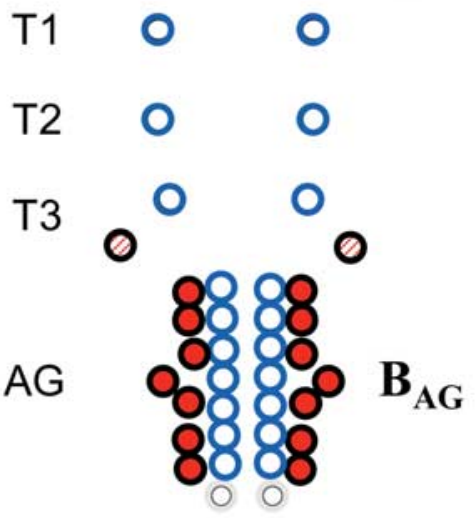

B

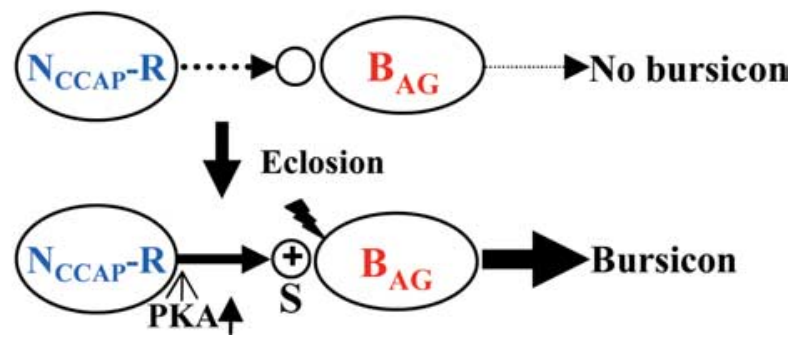

Figure 8. A model for the regulation of bursicon release by $\mathrm{N}_{\text {CCAP }}$ neurons. $A$, Manipulations of neuronal activity made with C929-Gal4 and CCAP-Gal4 distinguish two subsets of $\mathrm{N}_{\text {CCAP, }}$ one consisting of neurons always (black circles) or sometimes (gray circles) within the c929-Gal4 expression pattern ( $\left.\mathrm{N}_{\text {CCAP }}-\mathrm{C} 929\right)$, the other consisting of the rest of $\mathrm{N}_{\text {CCAP }}\left(\mathrm{N}_{\text {CCAP }}-\mathrm{R}\right.$, blue circles). $\mathrm{N}_{\text {CCAP }}-\mathrm{C} 929$ includes most of the bursicon-expressing neurons, which are shown in red. Dark red indicates neurons that consistently expressed bursicon and consist primarily of neurons in the abdominal ganglion $\left(\mathrm{B}_{\mathrm{AG}}\right)$, all of which lie within $\mathrm{N}_{\mathrm{CCAP}}-\mathrm{C} 929$ and which secrete bursicon into the hemolymph. The two bursicon-expressing subesophageal neurons within $N_{C C A P}-R$ are designated $B_{S E G}$. Red stripes indicate neurons that expressed bursicon at low frequency and, in the case of the brain and subesophageal neurons, not at all in $9229-G a \mid 4$ animals. $\boldsymbol{B}, A$ model for the regulation of bursicon secretion from the $B_{A G}$ by $N_{C C A P}-R$. In the absence of a positive signal from $N_{C C A P}-R$, the $B_{A G}$ are electrically silent and do not secrete bursicon (top). However, stimulation of PKA in $\mathrm{N}_{\text {CCAP }}-R$ (presumably in the period around eclosion) causes release of a positive (possibly synaptic) signal (S) from these neurons, which results in the activation of the $B_{A G}$ and the secretion of bursicon (bottom). D, M, and V refer to dorsal, middle, and ventral dispositions of the neurons within the SEG.

sicon or alter secretion of the hormone into the hemolymph after eclosion. This observation implies that $\mathrm{B}_{\mathrm{AG}}$ are quiescent until stimulated after eclosion (Fig. $8 \mathrm{~B}$ ). This conclusion supports electrophysiological data from Manduca, which indicates that bursicon-secreting neurons receive little synaptic input until after eclosion when synaptic activity becomes continuous ( $\mathrm{P}$. Taghert, personal communication) (Reynolds, 1983). More work will be required to determine how NaChBac-EGFP expression in $\mathrm{N}_{\mathrm{CCAP}}-\mathrm{R}$ alters bursicon secretion into the hemolymph.

The role of synaptic communication in the $\mathrm{N}_{\mathrm{CCAP}}$ network Our results strongly support a role for synaptic transmission in the regulation of bursicon secretion. Inhibition of both dynamin and synaptobrevin function, by expression of UAS-Shi ${ }^{\text {ts1 }}$ and UAS-TNT, respectively, had no effect on wing expansion when expressed in $\mathrm{N}_{\mathrm{CCAP}^{-}}-\mathrm{C} 929$ alone, indicating that bursicon secretion is not dependent on these molecules. Our observation that both UAS-Shi ${ }^{\text {ts } 1}$ and TNT inhibit wing expansion when expressed throughout $\mathrm{N}_{\mathrm{CCAP}}$ therefore demonstrates that synaptic blockade in $\mathrm{N}_{\mathrm{CCAP}}-\mathrm{R}$, but not $\mathrm{N}_{\mathrm{CCAP}}-\mathrm{C} 929$, is necessary for bursicon release. Block of synaptic inputs onto bursicon-secreting neurons may mediate this effect, as indicated in the model shown in Figure $8 B$, although the efficacy of blockade in inhibiting wing expansion when applied before, as well as after, eclosion suggests the involvement of multiple synapses.

We are currently unable to explain the less penetrant effects of TNT on wing expansion compared with those of UAS-Shit ${ }^{\text {ts }}$. Tetanus toxin may not completely eliminate synaptic transmission. Alternatively, compensatory developmental responses to constitutive, rather than transient, block of synaptic transmission may be attenuating the effects of TNT. Changes in cellular physiology in response to TNT expression have been described previously in neurons (Baines et al., 2001).

\section{PKA is required for the regulation of bursicon secretion}

Two previous reports, both using enhancer-trap Gal4 lines not known to express in $\mathrm{N}_{\mathrm{CCAP}}$, hinted that PKA might play a role in wing expansion (Bantignies et al., 2000; Rodan et al., 2002). We show here that PKA activity is required within $\mathrm{N}_{\mathrm{CCAP}}$ for bursicon release. Inhibition of PKA within $\mathrm{N}_{\mathrm{CCAP}}-\mathrm{C} 929$ blocks neither tanning nor wing expansion. PKA is thus required within $\mathrm{N}_{\mathrm{CCAP}}-\mathrm{R}$ within the context of our model (Fig. 8 B). Although the targets of PKA in $\mathrm{N}_{\text {CCAP }}$ remain to be determined, one intriguing possibility is that PKA downregulates the Shaw channel, which has been proposed to be a PKA target in mushroom bodies (Delgado et al., 1998), to increase excitability and signaling in $\mathrm{N}_{\mathrm{CCAP}} \mathrm{R}$.

Additional work will be required to validate our model of $B_{A G}$ regulation (Fig. $8 \mathrm{~B}$ ) and to determine the functional roles of specific neurons within $\mathrm{N}_{\mathrm{CCAP}}-\mathrm{R}$. Related to this is the question of whether bursicon secretion from $\mathrm{B}_{\mathrm{SEG}}$ and $\mathrm{B}_{\mathrm{AG}}$ is coordinately or independently regulated. Interestingly, the $\mathrm{B}_{\mathrm{SEG}}$ neurons belong to $\mathrm{N}_{\mathrm{CCAP}}-\mathrm{R}$ and may themselves participate in regulating $\mathrm{B}_{\mathrm{AG}}$ function. The role of the four non-bursicon-expressing neurons within $\mathrm{N}_{\mathrm{CCAP}}{ }^{-} \mathrm{C} 929$ also requires additional investigation. Our data rule out a role for these neurons in regulating $B_{A G}$ by mechanisms sensitive to enhancement of excitability or suppression of PKA or neurotransmission, but it remains possible that they regulate $\mathrm{B}_{\mathrm{AG}}$ by other means.

The functionally oriented approach established here has allowed us, for the first time, to demonstrate that the molecularly related $\mathrm{N}_{\mathrm{CCAP}}$ neurons comprise all or part of a neuronal network that regulates bursicon secretion. Using this approach with enhancer-trap lines other than c929-Gal4 should allow us to resolve the functional identities of specific neurons within this network.

\section{References}

Bainbridge SP, Bownes M (1981) Staging the metamorphosis of Drosophila melanogaster. J Embryol Exp Morphol 66:57-80.

Baines RA, Uhler JP, Thompson A, Sweeney ST, Bate M (2001) Altered electrical properties in Drosophila neurons developing without synaptic transmission. J Neurosci 21:1523-1531.

Baker JD, Truman JW (2002) Mutations in the Drosophila glycoprotein 
hormone receptor, rickets, eliminate neuropeptide-induced tanning and selectively block a stereotyped behavioral program. J Exp Biol 205:2555-2565.

Bantignies F, Goodman RH, Smolik SM (2000) Functional interaction between the coactivator Drosophila CREB-binding protein and ASH1, a member of the trithorax group of chromatin modifiers. Mol Cell Biol 20:9317-9330.

Conover WJ (1999) Practical nonparametric statistics. New York: Wiley.

Cottrell CB (1962a) The imaginal ecdysis of blowflies. Detection of the blood-bourne darkening factor and determination of some of its properties. J Exp Biol 39:413-430.

Cottrell CB (1962b) The imaginal ecdysis of blowflies. Evidence for a change in the mechanical properties of the cuticle at the time of expansion. J Exp Biol 39:449-458.

Delgado R, Davis R, Bono MR, Latorre R, Labarca P (1998) Outward currents in Drosophila larval neurons: dunce lacks a maintained outward current component downregulated by cAMP. J Neurosci 18:1399-1407.

Dewey EM, McNabb SL, Ewer J, Kuo GR, Takanishi CL, Truman JW, Honegger HW (2004) Identification of the gene encoding bursicon, an insect neuropeptide responsible for cuticle sclerotization and wing spreading. Curr Biol 14:1208-1213.

Ewer J, Reynolds S (2002) Neuropeptide control of molting in insects. In: Hormones, brain, and behavior (Pfaff DW, Arnold AP, Fahrbach SE, Etgen AM, Rubin RT, eds), pp 1-92. San Diego: Elsevier Science.

Ewer J, Truman JW (1996) Increases in cyclic 3', 5' -guanosine monophosphate (cGMP) occur at ecdysis in an evolutionarily conserved crustacean cardioactive peptide-immunoreactive insect neuronal network. J Comp Neurol 370:330-341.

Fraenkel G, Hsiao C (1965) Bursicon, a hormone which mediates tanning of the cuticle in the adult fly and other insects. J Insect Physiol 11:513-556.

Halfon MS, Gisselbrecht S, Lu J, Estrada B, Keshishian H, Michelson AM (2002) New fluorescent protein reporters for use with the Drosophila Gal4 expression system and for vital detection of balancer chromosomes. Genesis 34:135-138.

Hewes RS, Park D, Gauthier SA, Schaefer AM, Taghert PH (2003) The bHLH protein Dimmed controls neuroendocrine cell differentiation in Drosophila. Development 130:1771-1781.

Hodge JJ, Choi JC, O'Kane CJ, Griffith LC (2005) Shaw potassium channel genes in Drosophila. J Neurobiol 63:235-254.

Honegger HW, Market D, Pierce LA, Dewey EM, Kostron B, Wilson M, Choi D, Klukas KA, Mesce KA (2002) Cellular localization of bursicon using antisera against partial peptide sequences of this insect cuticlesclerotizing neurohormone. J Comp Neurol 452:163-177.

Johns DC, Marx R, Mains RE, O’Rourke B, Marban E (1999) Inducible genetic suppression of neuronal excitability. J Neurosci 19:1691-1697.

Kiger Jr JA, O'Shea C (2001) Genetic evidence for a protein kinase A/cubitus interruptus complex that facilitates processing of cubitus interruptus in Drosophila. Genetics 158:1157-1166.

Kitamoto T (2001) Conditional modification of behavior in Drosophila by targeted expression of a temperature-sensitive shibire allele in defined neurons. J Neurobiol 47:81-92.

Laemmli UK (1970) Cleavage of structural proteins during the assembly of the head of bacteriophage T4. Nature 227:680-685.

Li W, Ohlmeyer JT, Lane ME, Kalderon D (1995) Function of protein kinase A in hedgehog signal transduction and Drosophila imaginal disc development. Cell 80:553-562.

Luo CW, Dewey EM, Sudo S, Ewer J, Hsu SY, Honegger HW, Hsueh AJ (2005) Bursicon, the insect cuticle-hardening hormone, is a heterodimeric cystine knot protein that activates $\mathrm{G}$ protein-coupled receptor LGR2. Proc Natl Acad Sci USA 102:2820-2825.

Mendive FM, Van Loy T, Claeysen S, Poels J, Williamson M, Hauser F, Grimmelikhuijzen CJ, Vassart G, Vanden Broeck J (2005) Drosophila molting neurohormone bursicon is a heterodimer and the natural agonist of the orphan receptor DLGR2. FEBS Lett 579:2171-2176.
Nichols R, Kaminski S, Walling E, Zornik E (1999) Regulating the activity of a cardioacceleratory peptide. Peptides 20:1153-1158.

Nitabach MN, Blau J, Holmes TC (2002) Electrical silencing of Drosophila pacemaker neurons stops the free-running circadian clock. Cell 109:485-495.

Nitabach MN, Wu Y, Sheeba V, Lemon WC, Strumbos J, Zelensky PK, White BH, Holmes TC (2005) Electrical hyperexcitation of lateral ventral pacemaker neurons desynchronizes downstream circadian oscillators in the fly circadian circuit and induces multiple behavioral periods. J Neurosci, in press.

O’Brien MA, Taghert PH (1998) A peritracheal neuropeptide system in insects: release of myomodulin-like peptides at ecdysis. J Exp Biol 201:193-209.

Paradis S, Sweeney ST, Davis GW (2001) Homeostatic control of presynaptic release is triggered by postsynaptic membrane depolarization. Neuron 30:737-749.

Park JH, Schroeder AJ, Helfrich-Forster C, Jackson FR, Ewer J (2003) Targeted ablation of CCAP neuropeptide-containing neurons of Drosophila causes specific defects in execution and circadian timing of ecdysis behavior. Development 130:2645-2656.

Park Y, Filippov V, Gill SS, Adams ME (2002) Deletion of the ecdysistriggering hormone gene leads to lethal ecdysis deficiency. Development 129:493-503.

Ren D, Navarro B, Xu H, Yue L, Shi Q, Clapham DE (2001) A prokaryotic voltage-gated sodium channel. Science 294:2372-2375.

Reynolds S (1983) Bursicon. In: Endocrinology of insects (Downer GH, Laufer H, eds), pp 235-248. New York: Liss.

Reynolds SE (1977) Control of cuticle extensibility in wings of adult manduca at time of eclosion-effects of eclosion hormone and bursicon. J Exp Biol 70:27-39.

Reynolds SE, Taghert PH, Truman JW (1979) Eclosion hormone and bursicon titers and the onset of hormonal responsiveness during the last day of adult development in Manduca sexta (L). J Exp Biol 78:77-86.

Rodan AR, Kiger Jr JA, Heberlein U (2002) Functional dissection of neuroanatomical loci regulating ethanol sensitivity in Drosophila. J Neurosci 22:9490-9501.

Sokal RR, Rohlf FJ (1995) Biometry. New York: Freeman and Company.

Spindler KR, Rosser DSE, Berk AJ (1984) Analysis of adenovirus transforming proteins from early region-1a and region- $1 \mathrm{~b}$ with antisera to inducible fusion antigens produced in Escherichia coli. J Virol 49:132-141.

Sweeney ST, Broadie K, Keane J, Niemann H, O’Kane CJ (1995) Targeted expression of tetanus toxin light chain in Drosophila specifically eliminates synaptic transmission and causes behavioral defects. Neuron 14:341-351.

Taghert PH, Truman JW (1982a) The distribution and molecular characteristics of the tanning hormone, bursicon, in the tobacco hornworm Manduca sexta. J Exp Biol 98:373-383.

Taghert PH, Truman JW (1982b) Identification of the bursicon-containing neurons in abdominal ganglia of the tobacco hornworm, Manduca sexta. J Exp Biol 98:385-401.

Truman JW (1973) Physiology of insect ecdysis. 3. Relationship between hormonal-control of eclosion and of tanning in tobacco hornworm, Manduca sexta. J Exp Biol 58:821-829.

Tublitz NJ, Evans PD (1986) Insect cardioactive peptides: cardioacceleratory peptide (CAP) activity is blocked in vivo and in vitro with a monoclonal antibody. J Neurosci 6:2451-2456.

Tublitz NJ, Truman JW (1985) Insect cardioactive peptides. II. Neurohormonal control of heart activity by two cardioacceleratory peptides in the tobacco hawkmoth, Manduca sexta. J Exp Biol 114:381-395.

White BH, Osterwalder TP, Yoon KS, Joiner WJ, Whim MD, Kaczmarek LK, Keshishian H (2001) Targeted attenuation of electrical activity in Drosophila using a genetically modified $\mathrm{K}^{+}$channel. Neuron 31:699-711. 